\title{
El Neotokio que nos prometieron
}

\section{Enrique Parra Albarracín}

\author{
Recibido: 15.09.2021 — Aceptado: 27.09.2021
}

\section{Titre / Title / Titolo}

Le NeoTokyo qu'on nous avait promis

The NeoTokyo that was promised

La Neo'Tokyo che ci era stata promessa

\section{Resumen / Résumé / Abstract / Riassunto}

Dos décadas antes de la elección de Tokio como sede para la realización de los $32^{\circ}$ Juegos Olímpicos en 2020, el mangaka Katsushiro Otomo vaticinó que estos no llegarían a celebrarse en una de sus obras más icónicas «Akira». Tras las bombas de Hiroshima y Nagasaki, la destrucción y reconstrucción masiva ha marcado la línea creativa de numerosos artistas del país del sol naciente. El manga y el anime, como es denominado comúnmente el cómic japonés y su animación, dan buena cuenta de ello y muchas de sus obras más célebres se centran en esta cuestión, retratando de manera recurrente múltiples visiones catastrofistas de un Tokio futuro. Por tanto, este artículo pretende recorrer las calles de la capital japonesa analizando el retrato que los más célebres autores de manga y anime han hecho de la arquitectura y el urbanismo nipón desde una óptica retrofuturista y postapocalíptica.

Deux décennies avant de choisir la ville de Tokio pour accueillir la trente-deuxième édition des Jeux Olympiques en 2020, l' auteur de Manga, la bande dessinée japonaise, Katsushiro Otomo prèdit que cela n' aurait pas lieu dans son chef $\mathrm{d}$ - oeuvre iconique «Akira». Certains évènements tels les bombardements sur les villes d' Hiroshima et Nagasaki en 1945 ont marqué spécialement la créativité de nombreux artistes et pays du soleil levant liés aux sujets de la destruction et la reconstruction massive. La bande déssinée japonaise et son animation, couramment appelés «le mangà et» l'»anime» rendent bien compte de cela, un grand nombre de chef d' oeuvres sont axés autour de ces sujets, inmortalisant de façon rècurrente múltiples visiones catastrophiques. Ainsi, l' objectif de cet article est, tout simplement, de parcourir les rues de la capitale japonaise dans le but d' analyser et de montrer le portrait que les plus cèlèbres auteurs de manga et d' anime ont tait de l' architecture et de l' urbanisme nippon à partir d' un point de vue rétro-futuriste et postapocalyptique.

Two decades before Tokyo was elected as the host city for the 32nd Olympic Games in 2020, the manga artist Katsushiro Otomo predicted in one of his most prominent works, «Akira», that these games wouldn't happen. After the bombings of Hiroshima and Nagasaki, mass destruction and reconstruction have influenced part of the creative line of work of many Japanese artists. Several of the most iconic Manga and Anime pieces, terms that refer to japanese comics and animation specifically, are examples of it. They recurrently focus on multiple catastrophic visions of a future Tokyo. Therefore, this article pretends to go across the streets of Japan's capital city, analysing how the most iconic Manga and Anime artists have portrayed both its architecture and urbanism from a retro futuristic and post apocalyptic perspective.

Due decenni prima della scelta di Tokyo come sede per la realizzazione della $32^{\mathrm{a}}$ edizione dei Giochi Olimpici nell'anno 2020, il mangaka Katsushiro Otomo predisse, in una delle sue opere più significative, "Akira», che tali Giochi non si sarebbero celebrati. Dopo le esplosioni nucleari di Hiroshima e Nagasaki, la ingente opera di distruzione e ricostruzione ha segnato la linea creativa di numerosi artisti del paese del sol nascente. Il manga e l'anime, come vengono comunemente denominati il fumetto giapponese e la sua animazione, sono un buon resoconto di ció, e molte delle opere piú celebri si centrano proprio su questo tema, ritraendo in modo ricorrente le molteplici visioni catastrofiche di una Tokyo futura. Questo articolo si propone di ripercorrere le strade della capitale giapponese, analizzando l'immagine che i piú famosi autori di manga e anime ci hanno lasciato dell'architettura e urbanistica giapponese partendo da una visione retro-futurista e post-apocalittica.

\section{Palabras clave I Mots-clé / Key words I Parole chiave}

Manga, anime, Tokio, arquitectura, ciudad.

Manga, anime, Tokyo, Architecture, cité.

Manga, anime, Tokio, architecture, city.

Manga, anime, Tokyo, architettura, cittá. 


\section{Introducción}

Todos los relatos de ciencia ficción tienen un cierto aspecto profético. En ellos, los autores tratan de explorar futuros cercanos y lejanos, realidades posibles y alternativas que tienen su origen en nuestra bien conocida realidad. A menudo, este punto de partida es un descubrimiento científico, un cataclismo o un futuro tan lejano en el que el mero concepto de «humanidad» queda desdibujado. Pero en todos ellos existe un aspecto que suma o resta verosimilitud al conjunto, y este aspecto es la arquitectura.

Para el cómic, al tratarse de un arte que mezcla texto e imagen, las localizaciones que sirven como escenario limitan la acción, pues de igual modo que las viñetas son la unidad básica de medida y secuencian el tiempo (Bordes, 31), la arquitectura organiza su espacio.

En la cultura japonesa el manga, como es conocido el cómic producido en territorio nipón, está estrechamente ligado al anime (termino que define la animación del mismo país). Esta unión, que no se da entre ambos medios en el resto del mundo, se debe a la propia idiosincrasia japonesa. Aunque no existe consenso en la fecha exacta del origen de estas historietas, y dado que la horquilla de la que se habla abarca varios siglos (Hernández Pérez, 83), si tomamos como su arranque las obras de Katsushika Hokusai (1760-1849) durante el periodo Edo, aún tardaríamos un siglo en ver el primer anime.

Desde sus inicios el anime estuvo ligado al manga en varios aspectos. El primero fue su manufactura cuasi artesanal. El proceso de animación, influido por los desarrollos técnicos de occidente, ha ido evolucionando hasta el actual Computer Generated Imagery (CGI) pero durante décadas el trabajo de ilustrar cada escena se hizo de manera manual, de forma prácticamente idéntica a la del cómic. En segundo lugar, las adaptaciones de un medio a otro han sido comunes desde el principio, buena prueba de ello es que menos de veinte años después de las primeras cintas de animación de las cuales existen registros, aparece la primera adaptación de un personaje

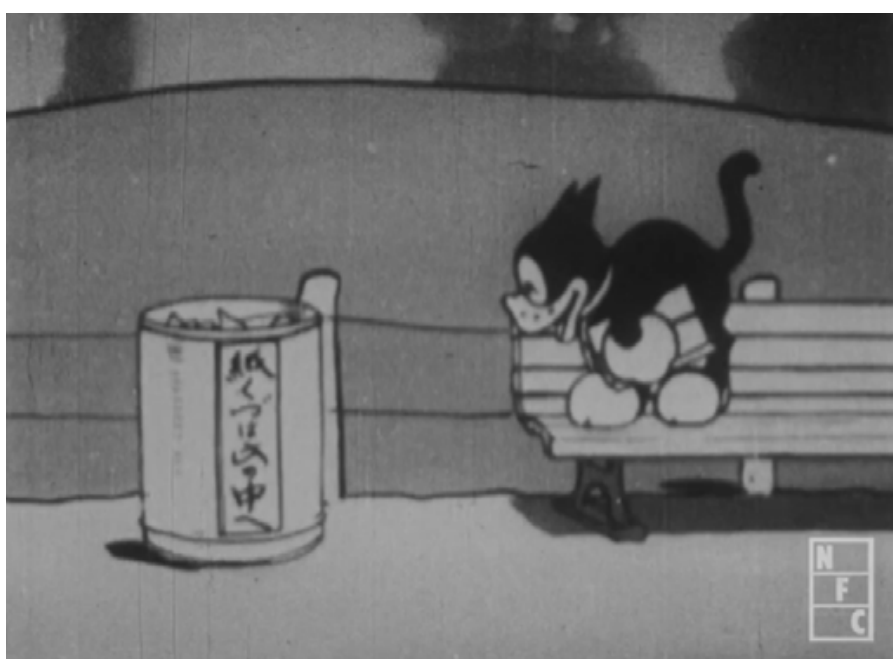

Figura 1. Corporal Norakuro, 1934. Fuente: Japanese Animated Film Classics

de un medio a otro (Hernández Pérez, 89) (Figura 1). Este hecho, lejos de ser algo puntual, se ha continuado hasta la actualidad de tal modo, que no solo es que aparezcan frecuentemente adaptaciones, si no que muchas sagas se lanzan de manera simultánea para los dos soportes. Esto ha provocado que sea común encontrar términos como manganime para referirse a este tipo de producción transmedia.

Uno de los responsables de este fenómeno, y conocido como «dios del manga», es Osamu Tezuka (19281989). Artista prolífico y polifacético, produjo obras tanto de manga como de anime dedicadas a públicos muy diferentes. Hay que entender, que a diferencia de sus homólogos occidentales, las producciones niponas se catalogan según la demografía a la cual van dirigidas además de por género. Así pues, encontraremos una sistematización muy precisa a la hora de clasificar a qué público va orientada cualquier obra. Dentro del legado inconmensurable que el maestro Tezuka dejó destacan obras como Astroboy, Metrópolis y Next World, todas ellas pertenecientes al género de la ciencia ficción.

Este autor, como el resto de su generación, quedó marcado por los estragos que la II Guerra Mundial provocó en su país, dejando el «pánico nuclear» una huella imborrable en muchas de sus obras. Ese mismo terror, imbuido en la historia japonesa por la devastación de 
Hiroshima y Nagasaki, se ha ido heredando por cada nueva generación de mangakas hasta nuestros días. Y es precisamente ese miedo hacia el desarrollo tecnológico en contraposición a la visión esperanzadora con que se abrazaron las corrientes futuristas llegadas a japón a principios del siglo XX el causante de haber moldeado uno de los subgéneros más importantes y extensos de la ciencia ficción: el Cyberpunk.

\section{Cyberpunj: High Tech, Low Life}

El cielo sobre el puerto tenía el color de una pantalla de televisor sintonizado en un canal muerto. Gibson, William. Neuromante. 1984

El Cyberpunk es un subgénero de la ciencia ficción caracterizado por una visión única de la tecnología, el desarrollo económico y el orden social. Surgido a principios de los años 80, esta corriente de la SfiCi apareció de manera simultánea en la cultura occidental y oriental en obras de diferentes disciplinas del arte (Palacios, 10:15). Calificado a menudo como corriente contracultural, sus planteamientos sobre los peligros del desarrollo tecnológico descontrolado, la sustitución del poder estatal por el de las megacorporaciones y un modelo de consumo próximo al anarcocapitalismo, reflejaban en gran medida la preocupación de los creadores de este estilo sobre la deriva que las relaciones políticas mundiales habían tomado, especialmente las encabezadas por Margaret Thatcher y Ronald Reagan.

Etimológicamente hablando, el término nace de las palabras Cyborg (abreviatura de Cybernetic Organism), la cual hace referencia a una forma de vida transhumana y tecnificada, y la palabra Punk, cuyo significado está próximo al de «suciedad» o «basura» y que determinó el nombre de un movimiento social marcado por el descontento y el espíritu rebelde. Así pues, el propio nombre de este género califica en gran medida la esencia de este, planteando propuestas ideales tremendamente tecnificadas pero llenas de angustia y sufrimiento. No

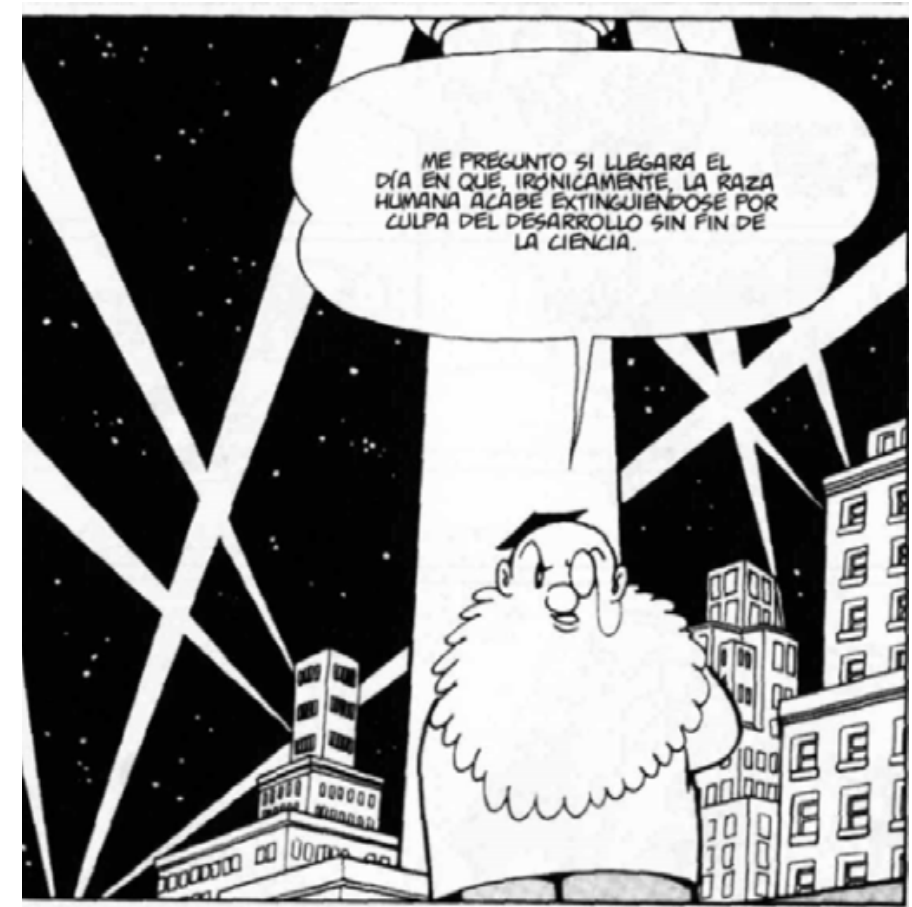

Figura 2. Tezuka, Osamu. Metrópolis. 1949

es casualidad que la expresión «High Tech, low life» sea una de las más repetidas para explicar el género, y es que la alta tecnología ligada a la pobreza extrema y la supervivencia urbana son algunas de sus señas de identidad.

Pero los orígenes del Cyberpunk se remontan a mucho tiempo atrás (Palacios, 22:35). Desde una óptica estrictamente occidentalista, encontraremos sus raíces entre la literatura callejera de los Pliegos de Cordel y los Penny Dredful del siglo XVIII y las Dime Novels del siglo XIX, entre las que se popularizó esa «baja literatura» de la que acabaría surgiendo la ciencia ficción, término que se acuñaría definitivamente en 1926 por Hugo Genrsbac en su revista Amazing Stories. Sin embargo, si planteamos esta búsqueda a través de la cultura oriental veremos que gran parte de las peculiaridades que distinguen este género están ligadas a la historia y eventos ocurridos en Japón a lo largo del siglo XX. En los primeros años 20, las vanguardias europeas irrumpieron con fuerza en el país nipón, y muy especialmente el futurismo, marcando a toda una generación de artistas que harían de este movimiento una seña de identidad 
nacional. Esto, unido al «Gran Terremoto de Kanto» y los posteriores planes de reconstrucción, dio lugar a un resurgir cultural en el que se abrazarían los avances tecnológicos como una forma de liberación de la humanidad. Pero este romance con la idealización de la tecnología vería su fin en agosto de 1945, cuando cayeron las bombas estadounidenses en Hiroshima y Nagasaki. El temor a que el desarrollo tecnológico acabase con la humanidad caló en el mundo entero, pero especialmente en la sociedad japonesa, la cual quedó tan traumatizada que la destrucción de sus propias ciudades sería un tema recurrente desde entonces en innumerables obras de todas las disciplinas artísticas (Figura 2).

Son muchos los considerados padres del Cyberpunk, pero lo cierto es que sería tremendamente injusto otorgarle el mérito a un único creador. Por tanto, podemos plantear cuáles son las obras fundacionales del género y quiénes los autores que más han dotado al mismo de sus características principales. Nos referimos, como no puede ser de otra manera, en un primer término a Blade Runner (Ridley Scott, 1982), Neuromante (William Gibson, 1984) y Akira (Katsushiro Otomo, 1982). Tres obras de tres disciplinas, cine, literatura y cómic, que marcaron las bases de un género que cuatro décadas después sigue evolucionando y creando nuevos títulos año tras año. Como decíamos, estos creadores no han sido los únicos, ni siquiera estas las primeras obras, pero sí las más destacadas e influyentes. Otros autores como Bruce Sterling, Pat Cadigan, Philip K. Dick, Moebius, Masamune Shirow o las hermanas Wachowski, han ido añadiendo capa tras capa hasta crear un género rico en matices que más allá de haber conseguido una estética y ambientación propia ha sabido elaborar todo un discurso crítico sobre hacia dónde se dirige la humanidad. Y es que estamos ante una de las corrientes con más carga filosófica de la SciFI. Por tanto, encontraremos conexiones y planteamientos similares en todas sus obras, aunque los desarrollos narrativos poco tengan que ver.

Uno de los primeros puntos de contacto es, como ya hemos comentado, el desarrollo tecnológico, y muy especialmente el que tiene que ver con la biomedicina. Implantes cerebrales, mejoras musculares, órganos ci- bernéticos y prótesis mecánicas son tema recurrente en este tipo de relatos. Más allá de ser una apuesta segura de hacia donde están evolucionando las técnicas sanitarias, sirven para plantear cómo se ha ido imponiendo un culto al cuerpo y unos cánones de belleza artificiales que arrastran a los individuos a modificar completamente su físico. Hecho que nos lleva a reflexionar sobre la dualidad alma y materia (Figura 3), ¿cuántas partes de nuestro cuerpo pueden ser sustituidas hasta que se nos pueda dejar de considerar humanos? Esta podría ser, a modo de resumen, una de las preguntas más trascendentales que los protagonistas se harán por el lector en la mayoría de las obras del género.
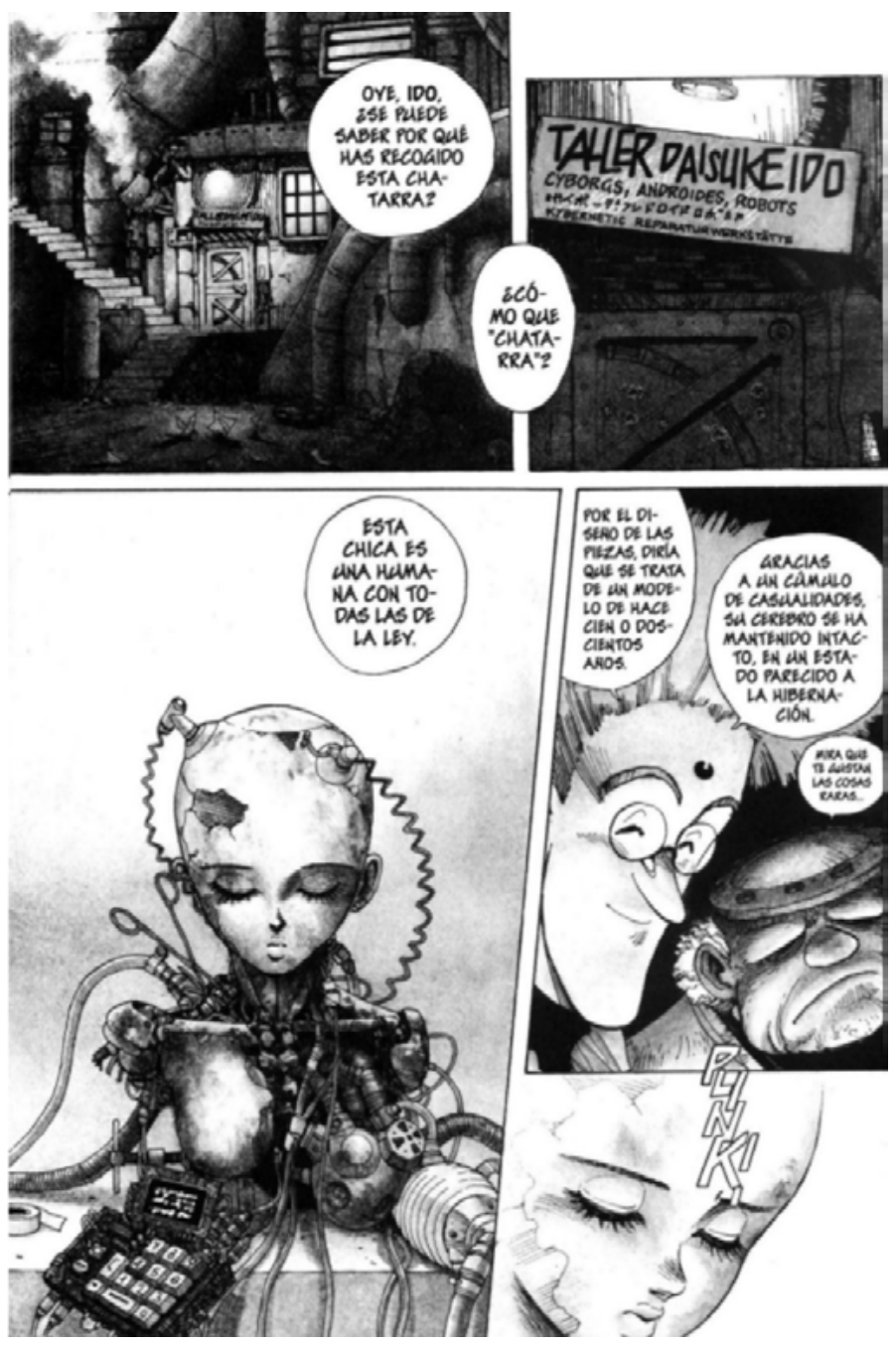

Figura 3. Gunnm. Kishiro, Yukito. Gunnm. 1990 
Otro de los temas recurrentes es la gestión de la información. En las obras del género, los personajes se ubican en situaciones en las que el mundo físico y el digital prácticamente se han fusionado o invadido mutuamente, haciendo necesarios esos implantes que comentábamos anteriormente. Además, esta información es abundante e invasiva. Se cuela a través de las pantallas publicitarias que han tomado la ciudad e incluso en los propios sistemas de telecomunicación. Esta información a menudo está manipulada para favorecer a los poderes fácticos, así como para engañar y doblegar la voluntad de una ciudadanía que hace lo que puede por sobrevivir. Esta suerte constructo social creado por los Mass Media acaba por aceptarse como la realidad, que mueve la información de una manera tal que es capaz de anestesiar cualquier movimiento revolucionario a la vez que reescribe la historia en su propio beneficio.

¿Y quién hay detrás de esos Mass Media que manejan la información y moldean la «Hiperrealidad»? Pues ni más ni menos que megacorporaciones que han adquirido más poder que los propios estados y que son quienes realmente manejan la sociedad. Este sistema, en el cual la democracia ha sido privatizada o directamente suprimida, trata a los individuos como engranajes fácilmente sustituibles de la gran maquinaria empresarial que lo controla absolutamente. Esto provoca la deshumanización paulatina de quienes están inmersos en esta maraña anarcocapitalista, devorando a quienes están abajo al tener que renunciar a su humanidad para poder sobrevivir y a los de arriba presa de su propia paranoia y los delirios de poder. Esta estratificación social tan enorme en una sociedad acostumbrada a la ultra violencia empuja a muchos de los habitantes de las zonas desfavorecidas a la delincuencia y a un consumo de drogas generalizado, haciendo aún más grande la brecha social.

$\mathrm{Y}$ es que, en este caso, hablamos de una corriente eminentemente urbana, donde la ciudad no es solo un escenario donde se desarrolla la acción, si no uno de las protagonistas principales y sin la cual difícilmente tendría sentido nada. Las ciudades retratadas en la práctica totalidad de las obras Cyberpunk son oscuras y hostiles. Parecería que siempre fuese de noche y estuviese llovien- do, con basura acumulada en cada rincón y luces de neón tintineantes en cada fachada. Estos ambientes a medio camino entre la iconografía del noir y la estética futurista, consiguen aglutinar una arquitectura neoclásica con el diseño más vanguardista. Pero lejos de plantearse como una solución utópica, las urbes del género funcionan a modo de ratonera para quienes las habitan, impidiéndoles huir a cualquier parte. En el Cyberpunk el fin del mundo es el fin de la ciudad, más allá no hay nada.

\section{Un laberinto de asfalto y luces de neón}

El cielo y el suelo son negros, como una pantalla en la que
aún no se haya dibujado nada; en el Metaverso siempre es de
noche, y la Calle es siempre chillona y está llena de luces, como
un Las Vegas libre de las restricciones de la física y las finanzas.
Pero los habitantes del vecindario de Hiro son muy buenos
programadores, así que es de buen gusto. Las casas parecen au-
ténticas. Hay un par de reproducciones de Frank Lloyd Wright
y varios caprichos victorianos. Stephenson, Neal. Snow Crash. 1992

Como afirman García Gómez y M. Pavón en Ciudades de Cine, cada metrópoli en el universo fílmico tiene una personalidad identitaria, donde el retrato urbano suele partir de la representación de hitos y panorámicas urbanas. Este planteamiento es igualmente cierto para el cómic, pero, eso sí, adaptado al formato. Cabe destacar que, si la relación entre cine y cómic en la cultura occidental es estrecha, en el caso de la industria japonesa la línea que los separa es delgada y difusa, como ya se explicó al origen de este texto al hablar de los proyectos transmedia.

El punto de partida suelen ser grandes ciudades reales vistas en un futuro cercano mutadas por la gran expansión tecnológica y económica. En esa mezcla entre lo real y lo ficticio, es común la hibridación de ciudades diferentes presentadas como una misma, e incluso la presentación de una ciudad como otra, es decir «ciudades mezcla» y «ciudades travestidas» tal y como las denominan García Gómez y M. Pavón. De esta manera los creado- 
res juegan con el ideario mental colectivo que tenemos de determinadas ciudades, para retorcerlo y replantearlo desde un punto de vista perverso.

Existe, además, una serie de tipologías asociadas a este tipo de relatos. La principal y más llamativa es la sede de la megacorporación que domina, y a menudo subyuga, al resto de la ciudad. Presentada desde diferentes estilos, a veces con una estética neoclásica para transmitir la sensación de antigüedad a veces como alarde tecnológico para mostrar su vanguardismo científico, siempre se muestran como un elemento de exhibición que sirve como muestra de poder y recordatorio constante de en manos de quién reside la soberanía de la ciudad. Otra de las tipologías descritas es la de vivienda mínima. El origen de su importancia y la constante repetición de esta viene del hacinamiento paulatino de las clases bajas, esto unido a la dualidad entre la realidad la «física» y la «virtual» hace que en muchas ocasiones estas viviendas no sean más que una única habitación tecnificada, buen ejemplo de esto es la vivienda de la inspectora Akane Tsunemori en Psycho Pass (Hikaru Miyoshi, 2018) donde además toda la decoración es holográfica y cambia según las apetencias de su moradora (figura 4).

No deja de llamar la atención a los lectores la continua aura de soledad reinante en este tipo de relatos. Por una parte, los protagonistas presentarán un arquetipo personal en el que sus relaciones sociales sean escasas, cuando no directamente inexistentes, y a menudo tóxicas, pero es que, además, la atmósfera opresora de cada emplazamiento subrayará este hecho. Desde las

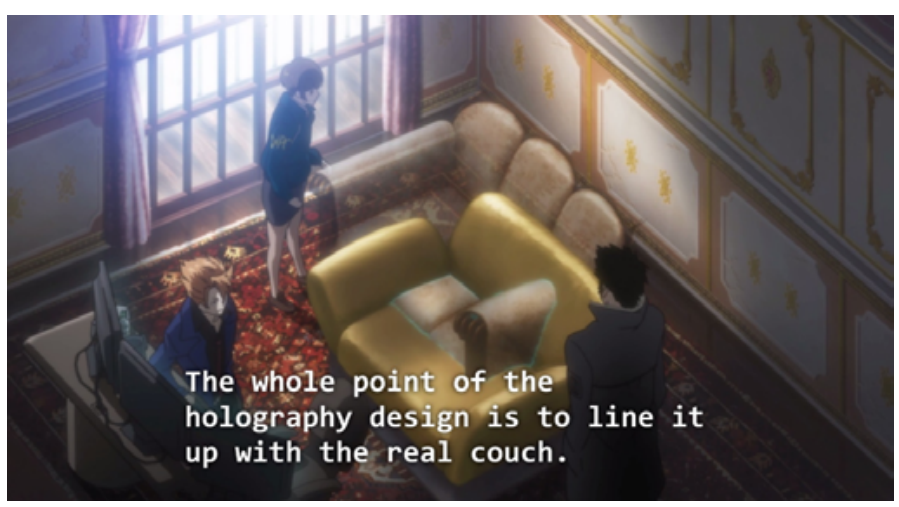

Figura 4. Shiotani, Naoyoshi. Psyco Pass. 2013

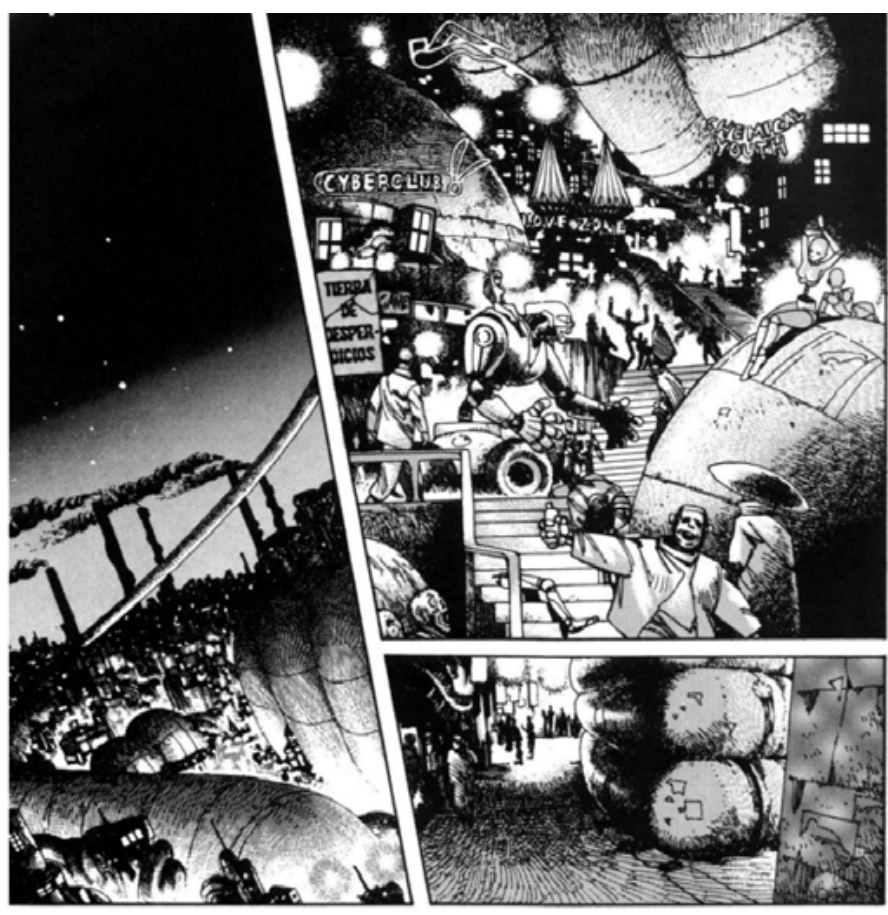

Figura 5. Kishiro, Yukito. Gunnm. 1990

ciudades rebosantes de vida como el «Patio de los Desperdicios» retratado por Yukito Kishiro en GUNNM (Kishiro, 1990) (Figura 5), a las galerías desoladas que Tsutomu Nihei proyectó para «La Ciudad» en BLAME! (Nihei, 1998), la sensación de desamparo y tensión acaba traspasando los límites del papel.

En definitiva, y siguiendo el método de clasificación descrito por Valentín Serrano García en Las Ciudades Imaginarias para las urbes ficticias, podremos reconocer las ciudades a través de sus representaciones metafóricas y metonímicas, es decir, mediante planos generales y vistas en detalle. En el caso de las calles del Cyberpunk, incluso para las avenidas virtuales, esto se traduce en una serie de normas de estilo establecidas gracias a las obras fundacionales del género. De este modo, para reconocer una ciudad Cyberpunk debemos observar los siguientes aspectos:

Metafóricos: Debe tratarse de una extensión urbana enorme, solamente comparable con las ciudades reales de mayor envergadura como Los Ángeles o CD México. Pero también debe tener una densidad extrema, 
especialmente cuanto más se aproxime a su centro neurálgico. El skyline debe ser heterogéneo, yendo de más bajo en los extremos a más alto en el centro, y teniendo siluetas identificables que destaquen sobre el conjunto.

Metonímicas: Probablemente sean los planos que den más riqueza al género. Como ya se ha comentado anteriormente, los planos interiores y exteriores de la sede de las megacorporaciones serán un recurso continuo, mostrando el poder y el lujo de estas. Sin embargo, será en la pequeña escala donde encontraremos un mayor número de matices. Talleres y clínicas clandestinas, tugurios frecuentados por compañías nada amigables y grandes avenidas conectadas a pequeños callejones donde se amontona una basura que no parece que vaya a ser recogida nunca, son algunos de los encuadres más repetidos. Pero si hablamos de la realidad virtual, aquí debemos tener en cuenta el desarrollo tecnológico desde los años 80, donde se sitúan las primeras obras del género, hasta la actualidad, por lo que encontraremos representaciones de los más ingenuas sobre un internet retratado como una especie de videojuego pixelado hasta una inmensidad tan vacía como abrumadora.

Para ejemplificar estas formas de abordar la arquitectura presente en las obras Cyberpunk se han escogido tres obras icónicas del género: Akira, Neon Génesis Evangelion y Ghost in the Shell. Obras maestras de sus creadores (Katsushiro Otomo, Hideaki Anno y Masamune Shirow \& Mamoru Oshii, respectivamente) en las cuales la ciudad Tokio en sus diferentes versiones y su arquitectura tiene un papel protagonista. Para ello, se utilizará el sistema de clasificación propuesto por Serrano García, el cual se podría agrupar en tres puntos clave:

- Pathos y ethos: la dialéctica única e intransferible entre la sociedad y su materialización urbana y arquitectónica. Pathos se refiere a la emoción y la expresividad visual mientras que Ethos habla de la forma de vivir de los habitantes de la ciudad.

- Metáfora y metonimia: manifestación visual a diferentes escalas de la ciudad a través de la cual se descubre el espacio.

- El mito: el mensaje que transmite cada una de las visiones de Tokio respecto a su homóloga real.

\section{Alkira by Katsushiro Otomo, 1982}

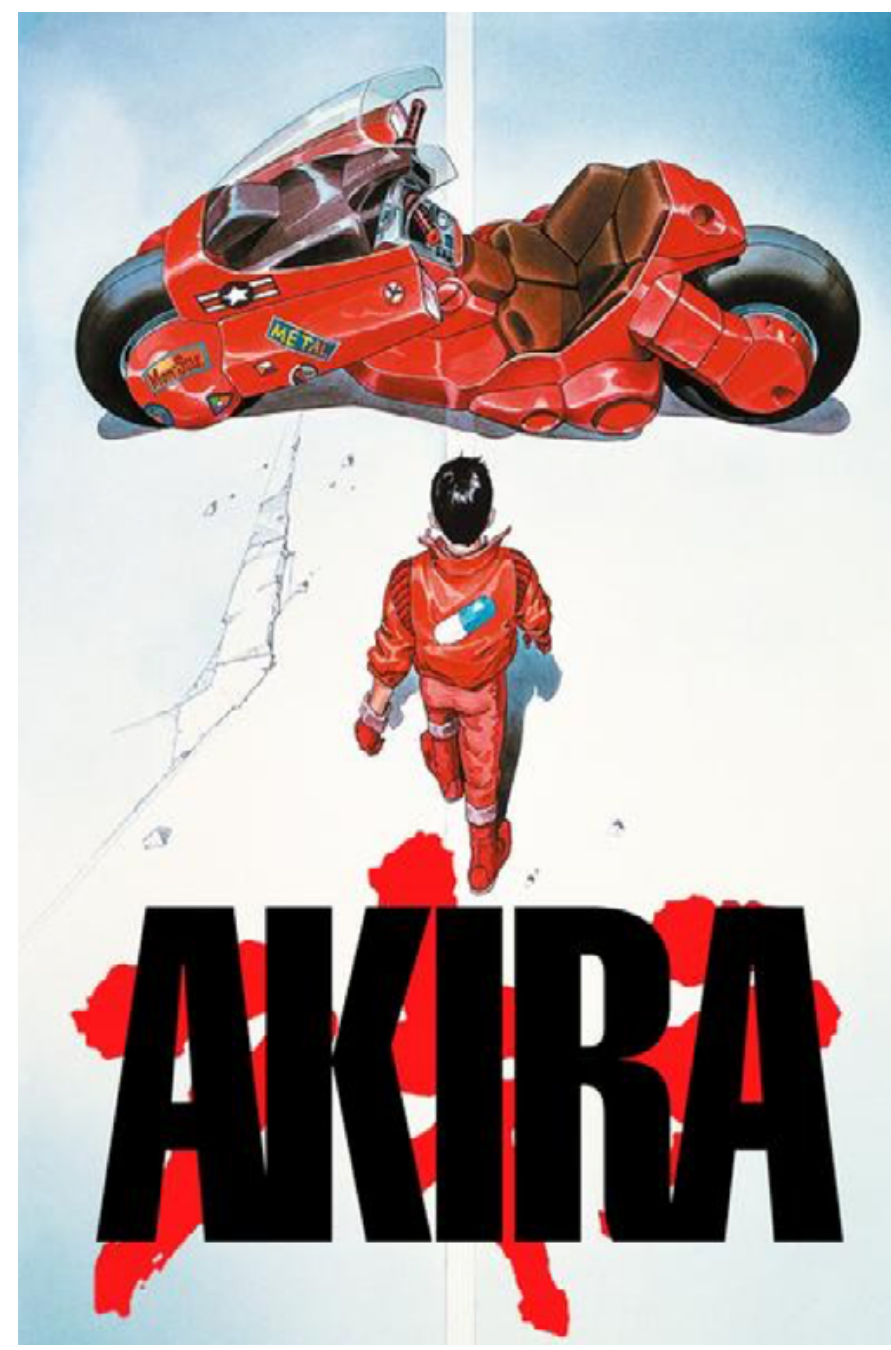

Figura 6. Otomo, Katsushiro. Akira. 1988

- Título Original: アキラ

- Idea Original: Katsuhiro Otomo

- Director Anime: Katsuhiro Otomo

- Dibujante Manga: Katsuhiro Otomo

- Año de primera publicación: 1982 manga, 1988 anime

- Extensión 6 tomos / $124 \mathrm{~min}$

- Género: Sci Fi, Cyberpunk

- Otras obras destacadas: Pesadillas, Memorias, Metrópolis, Steamboy. 


\subsection{Sinopsis}

En el año 2019 una banda de pandilleros juveniles trata de sobrevivir en las calles de Neo-Tokio, una nueva versión de la capital nipona reconstruida tras ser arrasada durante la tercera guerra mundial. Tratados como escoria en un sistema educativo que los da por perdidos, matan el tiempo enfrentándose a bandas rivales y consumiendo drogas. Una noche, tras una larga persecución en moto, Tetsuo (uno de los miembros de la banda) sufre un accidente de moto al cruzársele en la carretera un extraño niño que acto seguido desaparece. En poco tiempo su vida cambia para siempre ya que, después de lo sucedido, empieza a desarrollar poderes psíquicos y el gobierno lo secuestra para experimentar con él, descubriendo su potencial comparándolo al de algo o alguien llamado Akira. Mientras tanto, Kaneda (líder de la banda) se afana en un primer momento por intentar liberar y ayudar a su amigo junto a Kai y Ryu, miembros de una organización llamada «La Resistencia» que se opone al gobierno.

\subsection{Ethos y Pathos}

Tras ser arrasada durante la III Guerra Mundial en 1988 por una explosión nuclear según la versión oficial, Tokio es reconstruida junto a sus ruinas y se prepara para los Juegos Olímpicos de 2020. Esta nueva versión de la ciudad, cuya morfología es incluso más densa que la original, es retratada como una ciudad laberíntica y desigual, en la que contrasta la suciedad y decadencia de los bajos fondos con las luces y opulencia de los grandes rascacielos. Con una estratificación social completamente polarizada, gran parte de la población vive oprimida y abandonada a su suerte por el gobierno.

Figura 7. Vistas de Neo'Tokyo y Metrópolis. Fuentes: Otomo, Katsushiro y Lang, Fritz. Akira y Metrópolis;

El Neo-Tokio planteado por Otomo para Akira está inevitablemente relacionado con la Metrópolis de Fritz Lang (Figura 7), incluso encontraremos secuencias en
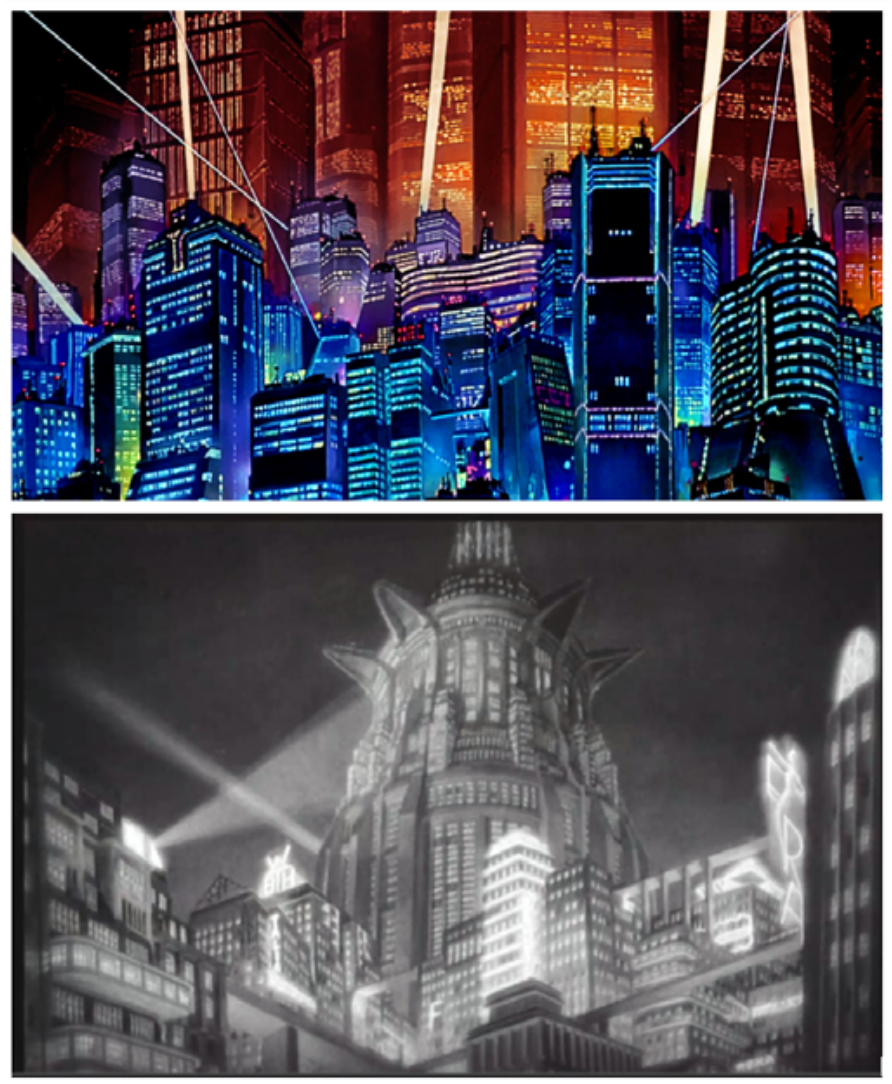

Figura 7. Vistas de NeoTokyo y Metrópolis. Fuentes: Otomo, Katsushiro y Lang, Fritz. Akira y Metrópolis

el anime dirigido por el propio Otomo que homenajean el film alemán. Además, la adaptación a anime del manga Metrópolis de Osamu Tezuka, a quien tanto influyó la obra de Lang y cuyo guion corrió a cargo Otomo, cierra el círculo que se originó con la inspiración de este al basarse en el barrio de las prostitutas de Tokio para esta obra cinematográfica de 1927.

Así pues, encontramos entre las páginas de Akira, y en su adaptación a anime, el relato de una ciudad desigual que sienta las bases junto a otras obras coetáneas de las urbes Cyberpunk (Figura 8). Sucias, hostiles, llenas de conductos imposibles, las calles son un laberinto tomado por las bandas callejeras a quienes les importa tan poco el bienestar del resto de la sociedad como al gobierno la suya.

Durante el principio de la narración Neo-Tokio se presenta como una ciudad envuelta con un halo de violencia, 


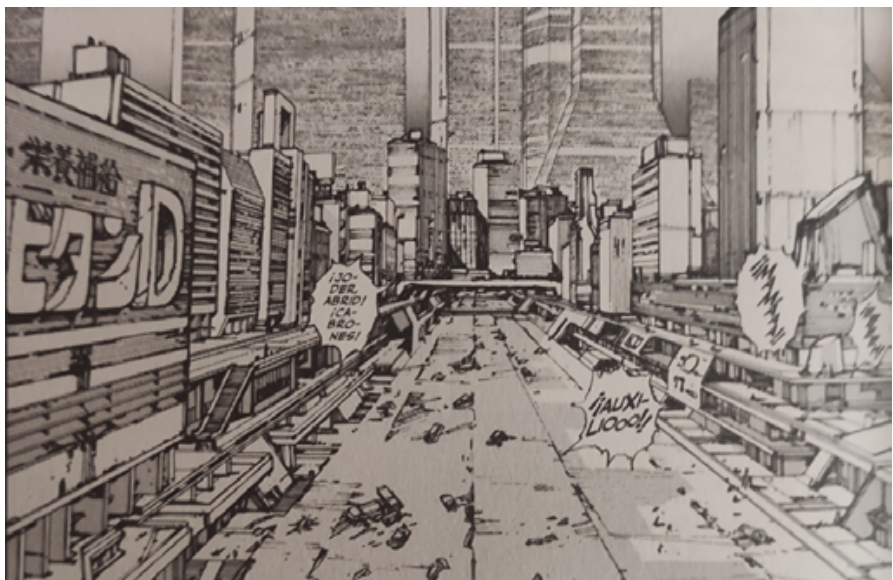

Figura 8. Otomo, Katsushiro. Akira. 1982

no solo por las bandas de motoristas pandilleros, si no por los disturbios de las continuas protestas ciudadanas. Mientras tanto, los rascacielos donde se sitúa el poder económico de la sociedad se retratan siempre como telón de fondo de los planos urbanos con una escala completamente desmesurada y una apariencia fría y hermética.

\subsection{Metáfora y metonimia}

Dada la magnitud de Akira, cerca de dos mil páginas de dibujo, y el estilo visual de Otomo, rico en detalles, encontramos una infinidad de paisajes urbanos. De entre todos ellos, existen algunas localizaciones que tienen especial interés desde un punto de vista arquitectónico, bien por el origen de la referencia o bien por la tipología planteada.

Los planos generales de Neo-Tokio muestran una y otra vez los gigantescos rascacielos como núcleo de una ciudad que a continuación disminuye en altura pero que se extiende por una gran superficie. Gracias al prólogo de la cinta, podemos comprar la versión anterior de Tokio con el nuevo planteamiento urbano, quedando patente cómo una ciudad ya de por sí caótica y densa se erige ahora como autentica cárcel urbana, asfixiante y laberíntica.

Pero es que Otomo va más allá y nos muestra en las primeras páginas del manga el cráter de la explosión y

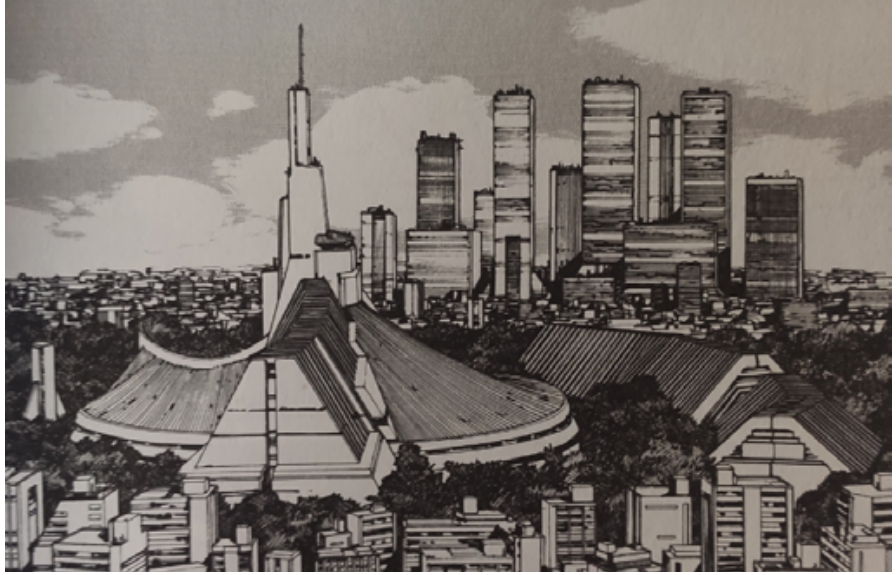

Figura 9. Otomo, Katsushiro. Akira. 1982

los restos despedazados de la ciudad antigua, edificios colapsados y el rastro de una onda expansiva que arrasó todo cuanto encontró a su paso.

Destacan en una visión más próxima las propuestas estéticas de los locales de juego como lugar de encuentro entre delincuentes (la bolera y los billares), el colegio de los pandilleros (retratado más como un reformatorio que como un espacio docente) y las calles de Neo-Tokio, vistas como auténticos circuitos urbanos para gozo y disfrute las bandas a lomos de sus motocicletas.

Son estos espacios que descubrimos mientras acompañamos a Tetsuo y su banda los que transmiten al espectador el ambiente de decadencia imperante en la sociedad de Neo-Tokio. Y a través de ellos es como se retrata el futuro de la juventud, arrinconada sin esperanza en una sociedad que no espera nada de ellos y cuya vida no puede entenderse más allá del consumo de drogas y la delincuencia.

Pero si Otomo ha demostrado algo con los escenarios en Akira ha sido ser un devoto de la arquitectura, y sobre todo, de saber usarla como elemento narrativo. En su obra aparecen referencias a la arquitectura de Nueva York o a edificios de Kenzo Tange, además de atreverse a retratar un hipotético estadio olímpico, pebetero incluido.

Este dominio le permite utilizar herramientas como la modificación de escalas para transformar lo infantil en grotesco, como pasa en la habitación donde tienen 
cautivos a los niños, o la utilización de la perspectiva para dotar de escala monumental tanto de los edificios pertenecientes al gobierno y las clases altas, como los espacios interiores de las cloacas y los laboratorios subterráneos.

Existe además un contrapunto a la arquitectura ortogonal y esbelta que domina el Neo-Tokio «otomoniano»: la cúpula de Akira. Si las líneas rectas dibujan una ciudad rígida e inexpugnable (dominio del gobierno y sus leyes), la curva se presenta sinuosa y caótica en las autopistas del extrarradio (dominio de la anarquía pandillera), lo esférico representa lo desconocido y lo temible, como es el caso del tanque de contención de Akira y la posterior explosión que volverá a arrasar todo una vez más (Figura 10).

\subsection{El mito de Neo-Tokio}

La revisión tokiota de Otomo ha trascendido a la mera ciudad genérica del Cyberpunk gracias a la expresividad con la que dibuja los rascacielos centrales de la ciudad que parecen acechar a los protagonistas y por transformar las calles en autopistas decadentes cuyo objetivo es ser el campo de batalla de un conflicto interminable entre pandilleros y fuerzas del orden.

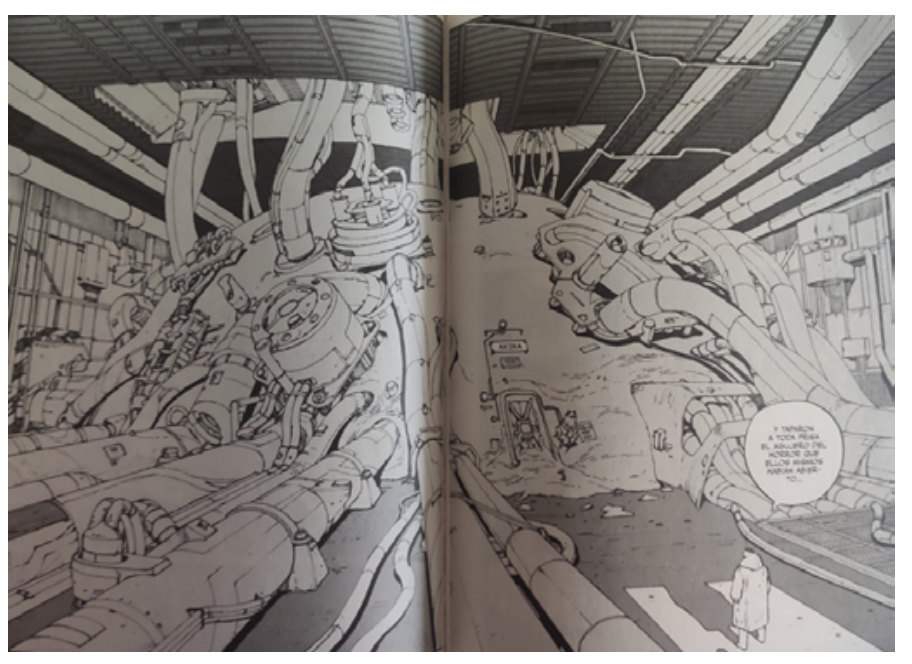

Figura 10. Otomo, Katsushiro. Akira. 1982

\section{Neon Genesis Evangelion, by Hideaki, anno 1995}

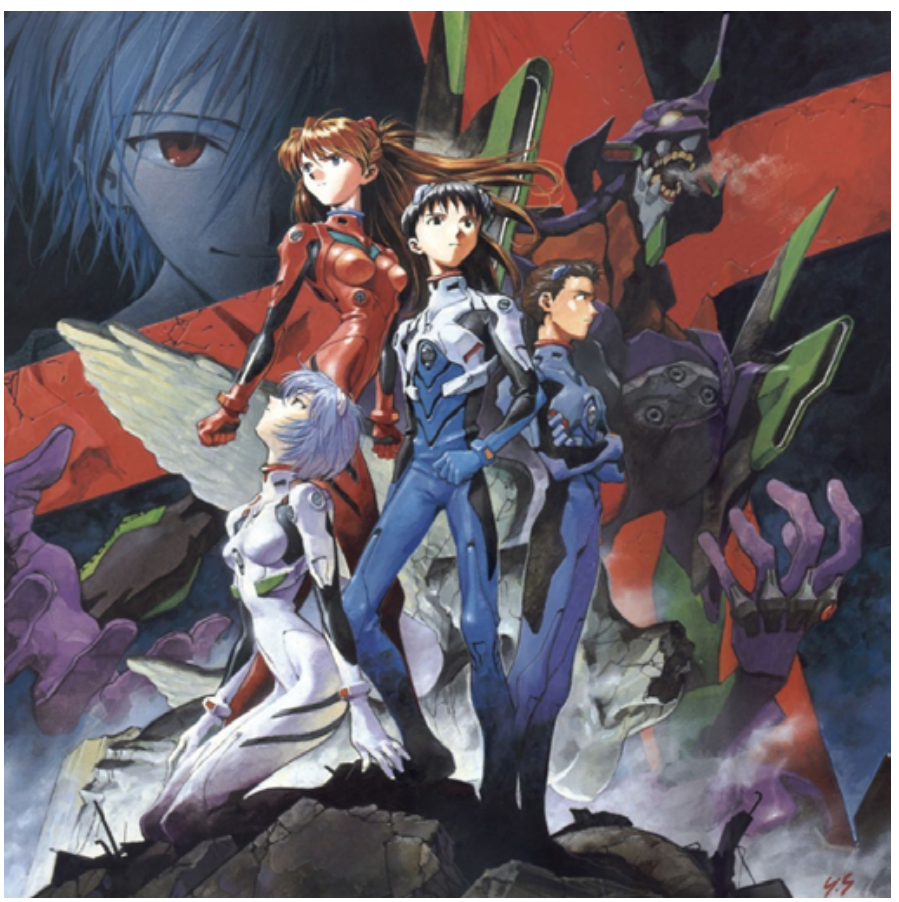

Figura 11. Gainax. Neon Genesis Evangelion. 1995

- Título Original: 新世紀エヴァンゲリオン (Shin Seiki Evangerion)

- Idea Original: Hideaki Anno

- Director Anime: Hideaki Anno

- Dibujante Manga: Yoshiyuki Sadamoto

- Año de primera publicación: 1995 anime, 1994 manga

- Extensión: 26 episodios anime, 14 volúmenes (manga)

- Género: Mecha, Cyberpunk, drama psicológico

- Otras obras destacadas: Gunbuster, Kare Kano, Shin Godrilla

\subsection{Sinopsis}

En 2015 la humanidad aún trata de recuperarse de la desaparición de la mitad de su población mundial debido a un evento ligado a la extinción llamado «Segundo Impacto» quince años atrás. La misteriosa organización 
Nerv desarrolla una serie de mechas llamados EVAs para luchar contra unos seres denominados «Ángeles», causante de dicho cataclismo. Shinji Ikari, un adolescente de quince años es llamado por su padre, Gendo Ikari, el cual lidera la organización, para que se convierta en el piloto del nuevo EVA.

\subsection{Ethos y Pathos}

Neon Genesis Evangelion desarrolla la práctica totalidad de la acción en la ciudad de Tokio-3, una nueva versión de la ciudad reconstruida tras el «segundo impacto». A diferencia de sus predecesoras esta ciudad está construida en base a dos escalas. Como el resto de metrópolis del mundo se toma la escala humana como referencia para el planeamiento y su arquitectura, pero esta nueva versión de la capital japonesa tiene la particularidad de que por sus calles se van a mover los EVAs.

Al tratarse de seres de gran tamaño dedicados a luchar contra «Ángeles», la ciudad se concibe como una fortaleza defensiva. Es por eso que Tokio-3 se alza sobre el Geofront (Figura 12), una gigantesca bóveda de $13,75 \mathrm{~km}$ de diámetro en la que se ubica la base de NERV. Además, los edificios de la ciudad cuentan con un sistema retráctil (Figura 13) que hace que una vez lanzada la señal de peligro se hundan hacia la bóveda quedando colgados sobre el vacío y dejando en el exterior únicamente las instalaciones necesarias que dan soporte logístico a los EVAs.

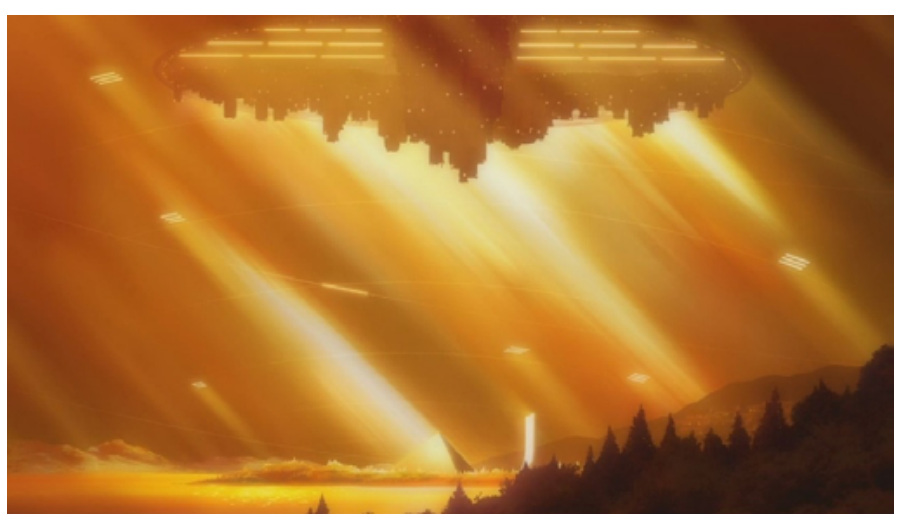

Figura 12. Gainax. Neon Genesis Evangelion. 1995
Este planteamiento de ciudad dual refleja el hecho de la doble función de esta, siendo a la vez un espacio habitable y un campo de batalla, una especie de ciudad fortaleza que debe preservar la vida pero que a la vez está equipada para el combate con la sede de NERV en su núcleo. Y es que, además, el planteamiento de la propia ciudad es ese, que sirva como escudo físico y metafórico de la organización. Sobre la superficie, los habitantes de Tokyo-3 no son conocedores de las operaciones de la organización, sólo saben el protocolo a seguir cuando suenan los avisos de la llegada de un nuevo ángel: huir lo más rápido posible a uno de los refugios.

Más allá de NERV, la vida en Tokyo-3 discurre con moderada normalidad. Han pasado quince años desde que el cataclismo que acabó con la mitad de la humanidad y con gran parte de los ecosistemas mundiales, pero a pesar de ello la actividad cotidiana se mantiene casi
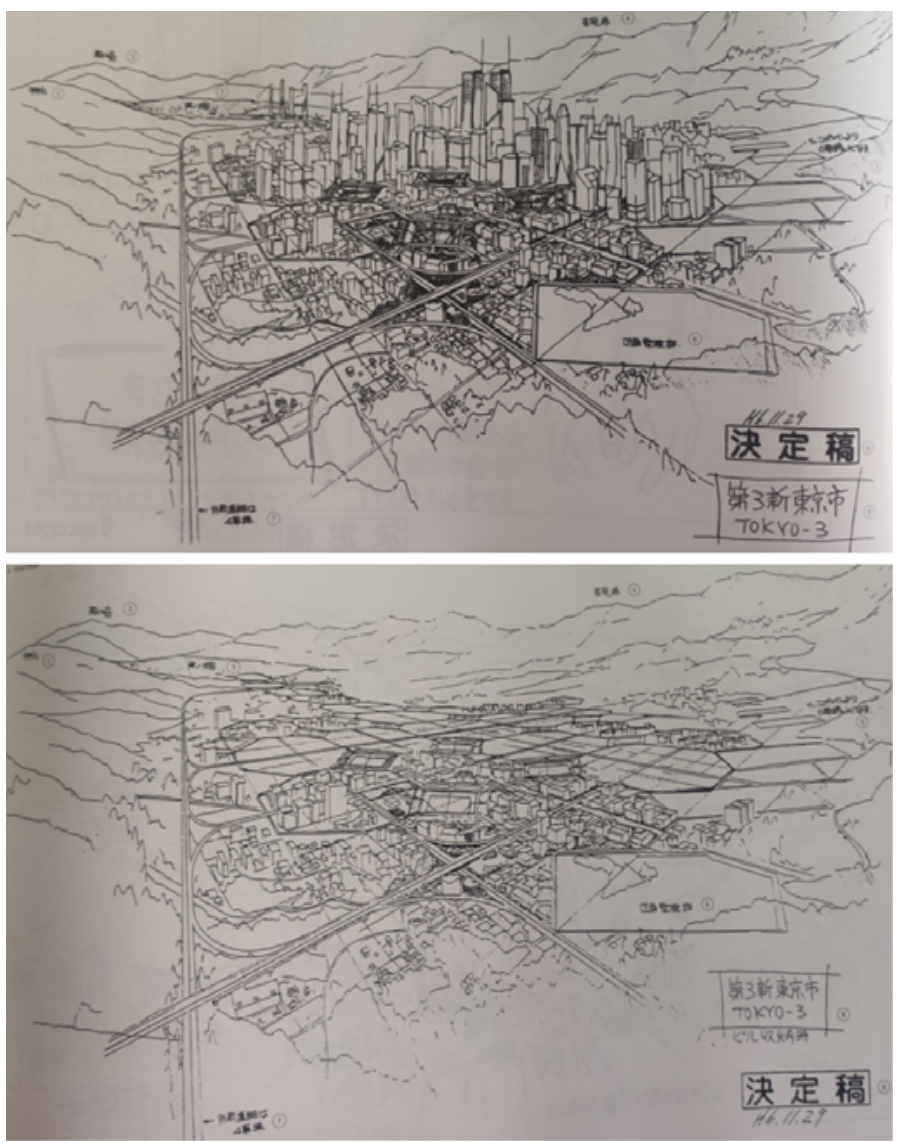

Figura 13. Gainax. Neon Genesis Evangelion. 1995 
como si nada hubiese ocurrido. Es más, estas mutaciones la ciudad son contempladas por los protagonistas de la serie como si de un bello espectáculo se tratase.

El ritmo de la serie, que salta del conflicto armado al drama adolescente con facilidad, nos lleva a recorrer una ciudad plena de actividad comercial y en las que los estudiantes mantienen sus rutinas y sus extraescolares como si nunca hubiese sucedido nada, salvo por el férreo control que NERV mantiene sobre toda la información de los habitantes de Tokio-3.

\subsection{Metáforas y metonimias}

Las primeras miradas a Tokio-3 llegan de la mano del protagonista de la serie, Shinji Ikari, y de su némesis, el primer ángel que se ve en quince años. Él, recién llamado por su padre, está buscando a la teniente Katsuragi para que lo lleve a las instalaciones de NERV, pero el conflicto no se hace esperar y pronto el enemigo aparece en escena rodeado por las fuerzas armadas de la UN.

En apenas los primeros minutos del primer capítulo ya se nos describe la tónica general de la serie, que irá saltando de la pausada vida cotidiana a la acción más frenética del combate a bordo de los EVA's. Es por eso que igualmente la ambientación irá alternándose entre las calles de Tokio-3 y el cuartel general de NERV, esa ciudad bajo la ciudad.

A pesar de ser concebida como un todo, la urbe de la superficie poco tiene que ver con la gigantesca bóveda que bajo ella se dispone. En el exterior apreciaremos un urbanismo racionalista trufado de arquitecturas más o menos convencionales de diferentes escalas. Un trasunto bastante creíble de lo que puede ser una ciudad nipona muchísimo menos densificada que el Tokio original y de unas dimensiones considerablemente más reducidas. La contrapartida la da el cuartel general de NERV, construido de manera hermética y cuya forma piramidal no es más que una de tantas referencias que la serie a diferentes religiones y mitologías.

Por otro lado, la exploración de ambas de Tokio-3 se nos irá presentando de manera sucesiva y apareja-
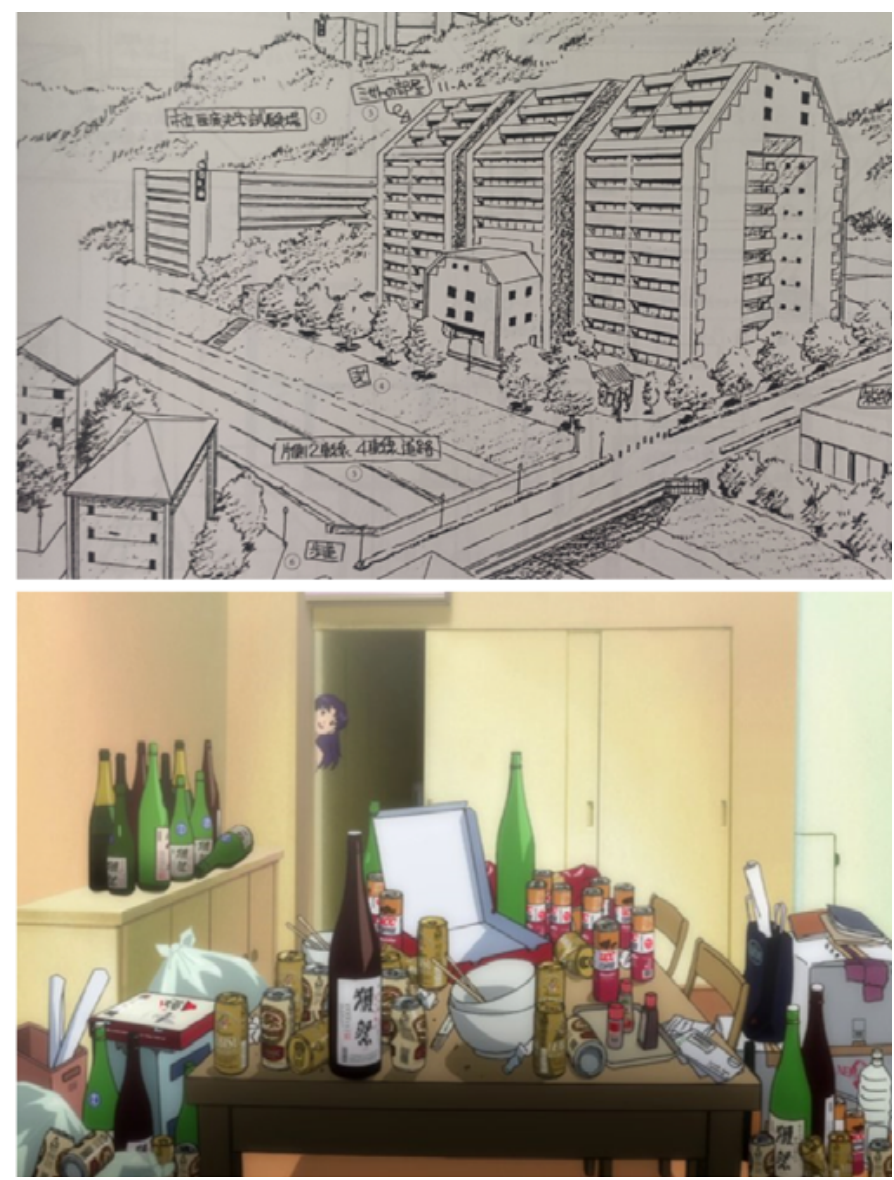

Figura 14. Gainax. Neon Genesis Evangelion. 1995

da a cada una de las facetas de los protagonistas. Eso sí, siempre discriminando si cada uno de los espacios pertenece a la superficie o al subterráneo a través de su diseño, su materialidad y su iluminación.

$\mathrm{Al}$ tratarse de una obra coral quedan retratadas una gran cantidad de localizaciones, en las cuales Anno se recrea detallando los quehaceres diarios del elenco protagonista. Gracias a los pilotos adolescentes descubriremos sus espacios docentes y domésticos, pero también recorreremos la laberíntica base de subterránea acompañando a la teniente Katsuragi y del resto del personal cientificomilitar.

Para la arquitectura educacional Anno recurre al arquetipo de escuela de secundaria tradicional, sin ningún tipo de modificación o tecnificación: aulas con pupitres individuales, largos pasillos con ventanas al patio y es- 

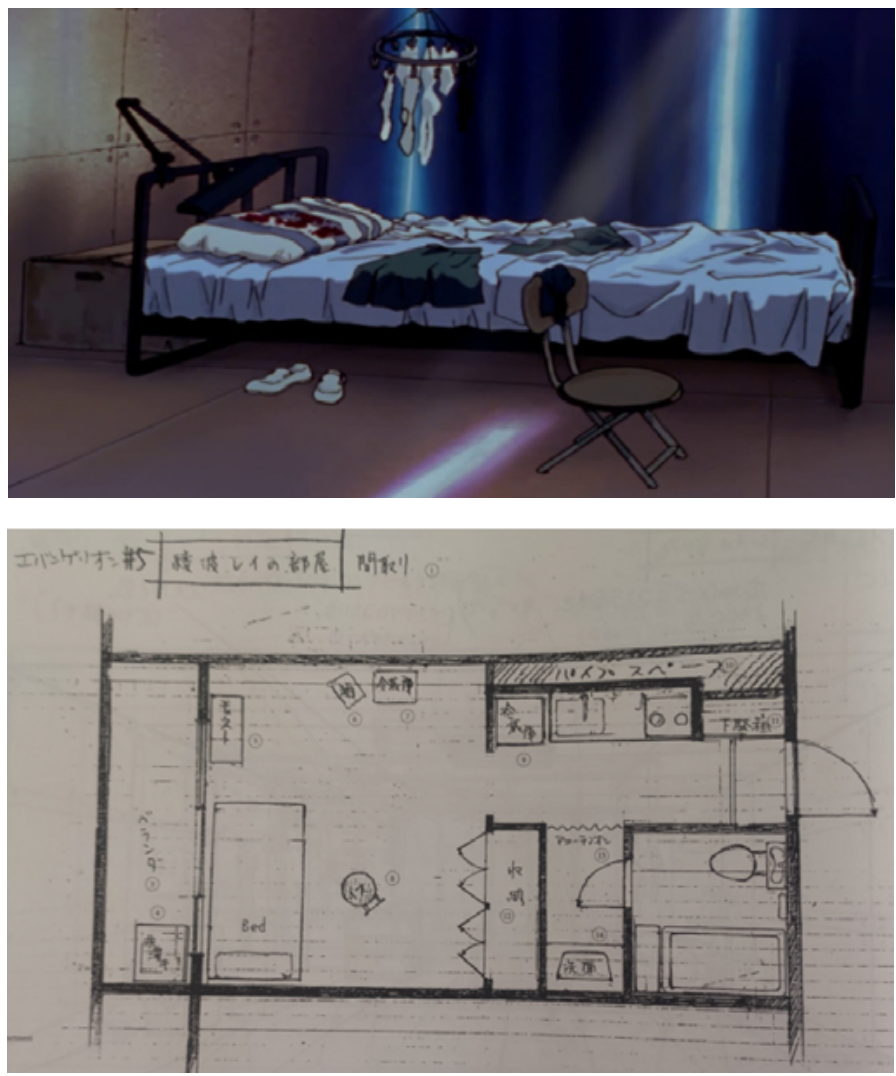

Figura 15. Gainax. Neon Genesis Evangelion. 1995

pacios abiertos donde practicar deporte, nada que haga pensar ni remotamente que se trata de un futuro Cyberpunk y apocalíptico. Exactamente igual sucede para los espacios domésticos, en los que podemos encontrar las tipologías japonesas de manshon マンシオン), es decir, lo que en occidente conocemos como vivienda colectiva, y los apaato (アパート), las viviendas de una sola estancia con la cocina en la entrada y un baño interior. En el caso de Evangelion, se usa la vivienda como un reflejo de la personalidad de cada personaje. Así, el piso de Katsuragi (Figura 14) donde acaban viviendo también Shinji y Asuka (otra de los pilotos), se muestra como desordenado y lleno de latas de cerveza, siendo el contrapunto personal a su faceta seria y dura en la vida profesional. En cuanto a Rei, la primera niña piloto de EVA, vive sola en un apaato, completamente vacío únicamente amueblado con una cama, mostrando la personalidad fría y vacía contra la que la propia Rei lucha durante toda la serie (Figura 15).

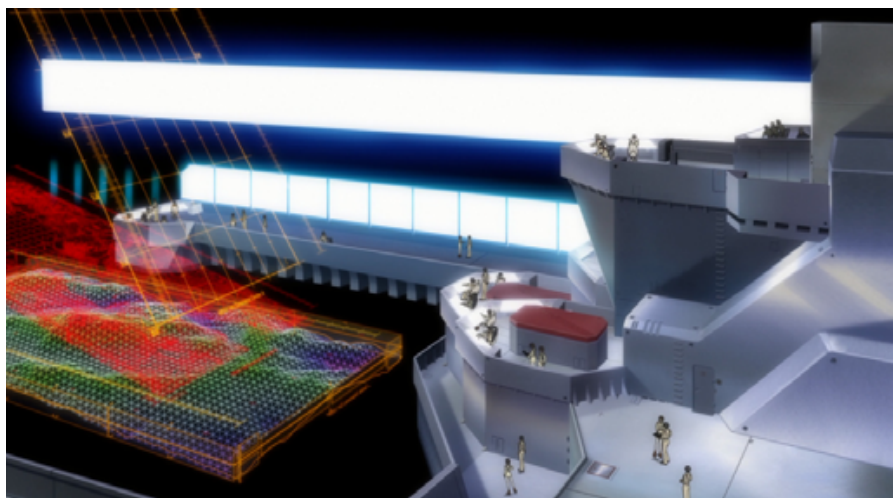

Figura 16. Gainax. Neon Genesis Evangelion. 1995

Por otra parte, la sede de NERV es la que confiere el carácter Cyberpunk a la serie. Con un aura de misterio que envuelve para el resto del mundo lo que ocurre en sus instalaciones, nada tiene que ver la ingeniería de su interior con la normalidad aparente del exterior. Sin duda, el contraste más grande lo hallaremos en la gran diferencia de escala de los espacios dedicados a los EVA's con respecto al de los humanos. Con una altura aproximada de $80 \mathrm{~m}$, no es de extrañar que las dimensiones de los espacios destinados al entrenamiento y la puesta a punto de estas «máquinas» estén más cercanas a las de un silo que a las de cualquier otra tipología.

Dadas las dimensiones de las instalaciones de NERV, no es de extrañar que todo el entorno se haya convertido en una maraña de túneles y pasadizos de una escala monumental, para la entrada y salida tanto del personal como de los EVAs, observándose incluso durante la narración el problema de esto cuando la tecnología falla y el transporte debe hacerse caminando a través de pasillos y escaleras que parecen perderse en el infinito.

Para subrayar la avanzada tecnología de la base, la mayor parte del mapeado y la información se representan mediante sistemas holográficos en el espacio dedicado al centro estratégico y la sala de mando, sin duda una de las aportaciones arquitectónicas más reseñables, consistente en un atrio de enormes proporciones e invadido por la información holográfica a al cual se abren una serie de pisos escalonados donde se reparten los trabajadores de NERV hasta llegar al punto más alto donde se encuentra el alto mando (Figura 16). Pero no 
es esta la única aportación espacial reseñable. Lugares como la sala del comandante, con un vacío atronador que subraya el distanciamiento de Gendo Ikari con el resto del mundo, o la sala de convalecencia del centro médico completamente fuera de escala, son usados para regodearse en la introspección de los personajes.

\subsection{El Mito de Tokio 3}

Hideaki Anno ha sabido aunar en una única ciudad el carácter bélico de su saga con la gran carga emocional que llevan sus protagonistas. Tokio-3 es a la vez un arca de salvaguarda y un arma, una fortaleza y un jardín. Es ante todo un hogar que sus habitantes luchan por defender y reconstruyen una y otra vez, batalla tras batalla, hasta que la humanidad o los «ángeles» acaben por imponerse.

\section{Ghost in the Shell by Masamune Shirow, 1989}

- Título Original: 攻殼機動隊 (Kōkaku Kidōtai)

- Idea Original: Masamune Shirow

- Director Anime: Mamoru Oshii

- Dibujante Manga: Masamune Shirow

- Año de primera publicación: 1995 anime, 1989 manga

- Extensión: 82 minutos, Manga: III volúmenes

- Género: Cyberpunk

- Otras obras destacadas: Appleseed, Orion, Dominion Tank Police

\subsection{Sinopsis}

En el año 2029 la humanidad ha traspasado los límites de la mortalidad gracias a la bioingeniería, que permite la reparación del cuerpo mediante prótesis cibernéticas e incluso el traspaso de una conciencia humana (ghost) a un cuerpo artificial. La mayor Matoko Kusanagi cuyo cuerpo es completamente cibernético, es miembro de la «Sección 9», unidad policial dedicada a delitos cyberte-

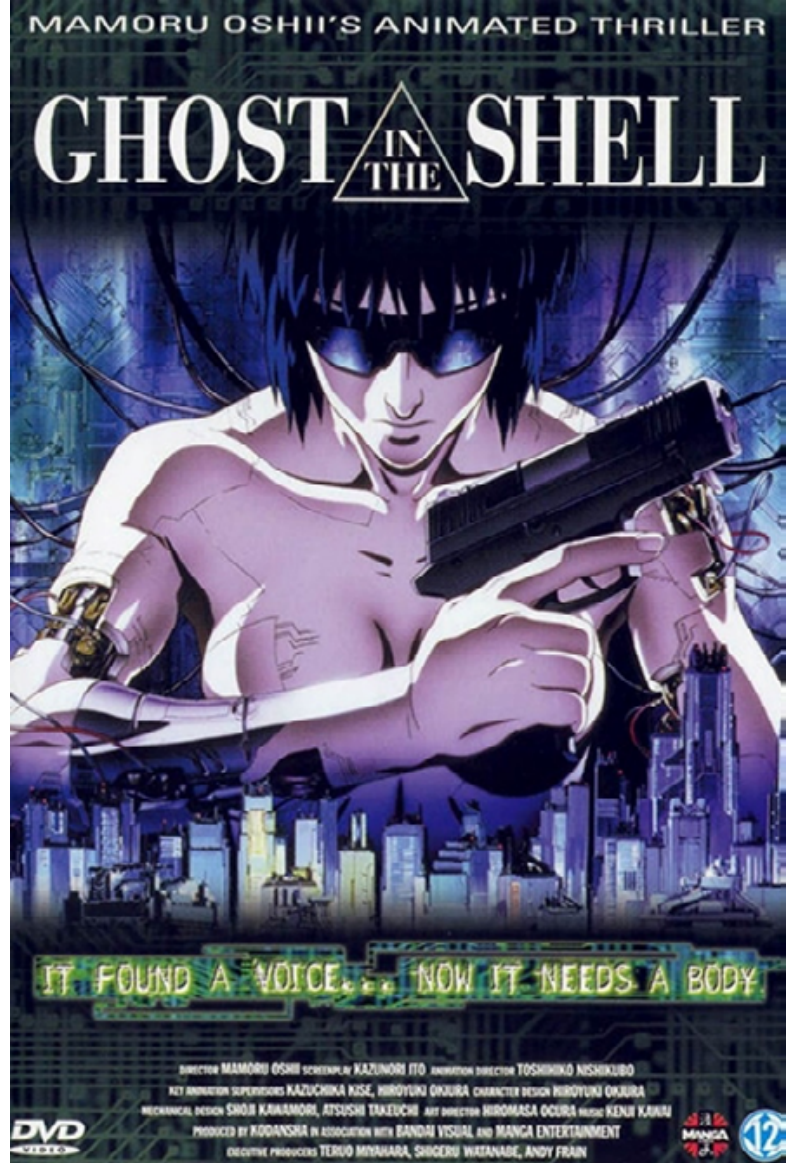

Figura 17. Oshii, Mamoru.Ghost in the Shell. 1995

rroristas, comienza a investigar unos misteriosos crímenes en los que los recuerdos de la gente son alterados y todo apunta hacia un enigmático personaje del que nadie parece saber nada: el Marionetista.

\subsection{Ethos y Pathos}

La ciudad en la que se desarrollan la mayoría de los acontecimientos de Ghost in the Shell es la metrópoli ficticia de New Port City, un trasunto de Hong Kong que se presenta como la capital del Japón (figura 18). En este Neotokio no encontramos grandes hitos reconocibles basados en edificios reales, si no que Shirow busca el anonimato de la ciudad para que esta pueda ser cualquier futura mega urbe asiática. 


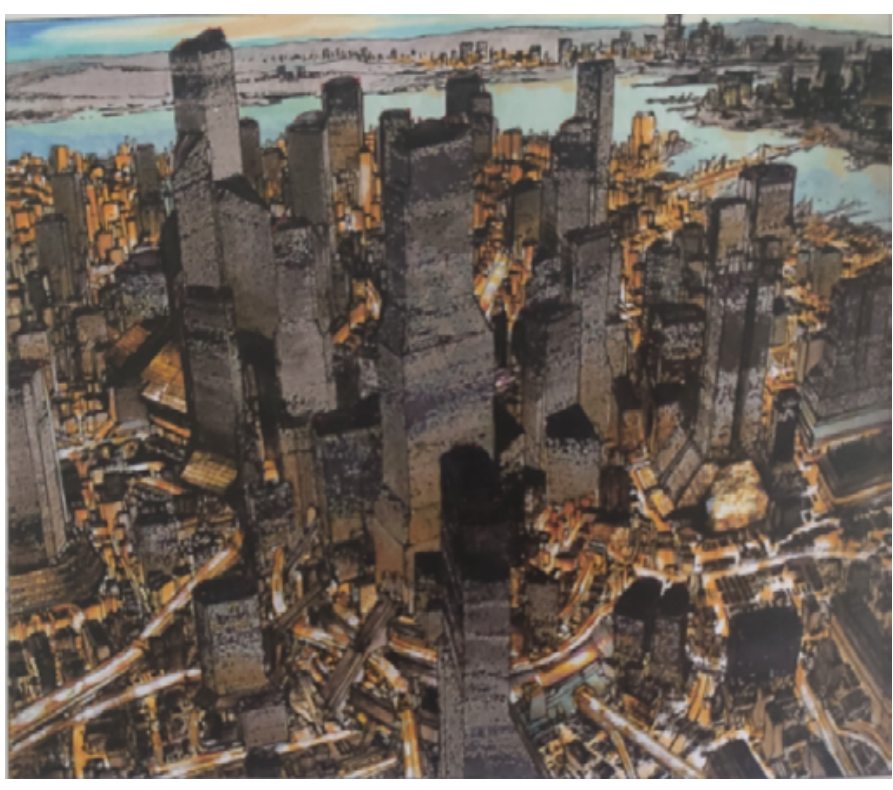

Figura 18. Shirow, Masamune. Ghost in the Shell. 1989

El conocimiento que el espectador tiene de New Port City se desarrolla gracias a los hechos en los que interviene la «Sección 9». Por tanto, al tratarse de un apartado de las fuerzas del orden ligadas a la cyberseguridad, nuestro paso por la urbe estará ligada a la acción e investigación de esta. De esa manera, descubrimos una ciudad narrada de manera dual, contrastando en todo momento el ambiente denso, tecnológico y financiero del distrito central, colmado de rascacielos y cuyas calles son dominadas por el tráfico rodado, con el suburbio extensivo del distrito costero, donde las calles son de un tráfico más pausado, bien sea por calles donde el tránsito es principalmente peatonal o por los canales por los que las embarcaciones navegan sobre aguas sucias.

Es precisamente esta contraposición constante de ambas formas de ciudad la que permite un mejor entendimiento de cómo es realmente habitar en ella: un centro financiero lleno de torres inexpugnables de vidrio y a acero frente a las barriadas de viviendas corrientes repletas de callejones, el alarde tecnológico de cualquier espacio urbano frente a los puestos callejeros y la infinitud de carteles publicitarios.

En las zonas de máxima compresión, se nos presenta una ciudad de lujo y crimen de guante blanco, don- de desarrollan sus vidas las clases más acomodadas. Es precisamente en una de las escenas más célebres, en la cual la mayor se desvanece frente a sus perseguidores mientras cae desde la cima de un rascacielos (Figura 18), donde la multiplicidad de los niveles de comunicación de la ciudad se manifiesta y donde se empieza a comprender que en esa zona de la ciudad la calle únicamente sirve para el transporte, no hay espacio para la vida más allá de las paredes de vidrio y hormigón, o al menos no para una vida de ese nivel.

No es casual que el retrato de ambas partes de la ciudad sea tan antagónico. El retrato enfrentado constante de los diferentes distritos permite entender los dos modos principales de habitar la ciudad. El de las clases dominantes, cuya vida se desarrolla en las alturas y en grandes espacios privados, frente al de las clases desfavorecidas que pasan sus días a muchos metros por debajo y en espacios públicos de pequeñas dimensiones, ya que las viviendas son mínimas.

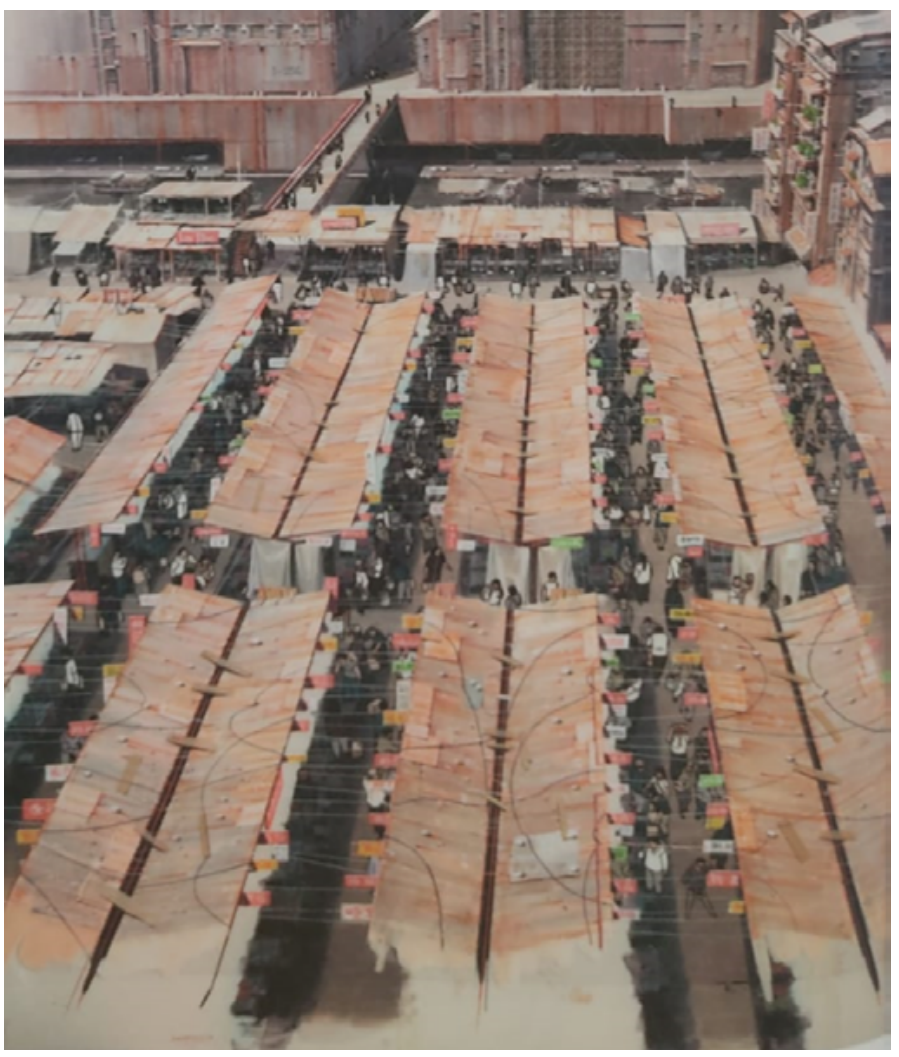

Figura 19. Kusamori, Shuichi. Ghost in the Shell. 1995 


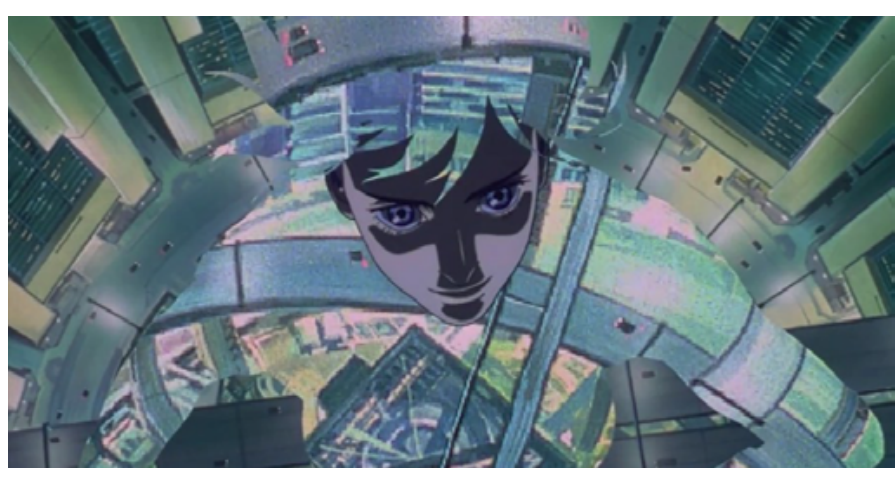

Figura 20. Oshii, Mamoru. Ghost in the Shell. 1995

Como buena urbe Cyberpunk, los barrios más desfavorecidos son presentados como laberínticos, sucios y llenos de callejones (figura 19). En la mayoría de ocasiones acompañaremos a la mayor Kusanagi, quien nos los mostrará como un reflejo de su propia crisis de identidad tras el traspaso de su ghost a un cuerpo artificial. Una ciudad llena de reflejos, con aparente vida, pero solitaria, plagada de repeticiones y contradicciones que veremos a través de los ojos de la protagonista en una de las escenas más introspectivas del anime (Queztzal, 6:50), en la que incluso acaba viendo a alguien con su mismo cuerpo llevando una vida completamente diferente a la suya a través del cristal de una cafetería.

Así pues, y como viene siendo habitual en el género, New Port City sirve no solo como plano situacional de la acción, si no que se convierte en un elemento narrativo que transmite al espectador la coherencia de la historia a la vez que sirve como recurso cinematográfico. No podría entenderse la estratificación social sin la visión opuesta del distrito financiero frente al suburbio, ni el diálogo interior de la protagonista sobre si es humana o es máquina a su tránsito por una ciudad ultra tecnificada y vacía frente una pobre pero llena de vida.

\subsection{Metáfora y metonimia}

Tanto Mashamune Shirow en su manga como Mamoru Oshii en el anime presentan New Port City inicialmente con vistas aéreas capaces de transmitir la tremenda escala de la urbe. Más allá de que esto pretenda ser una

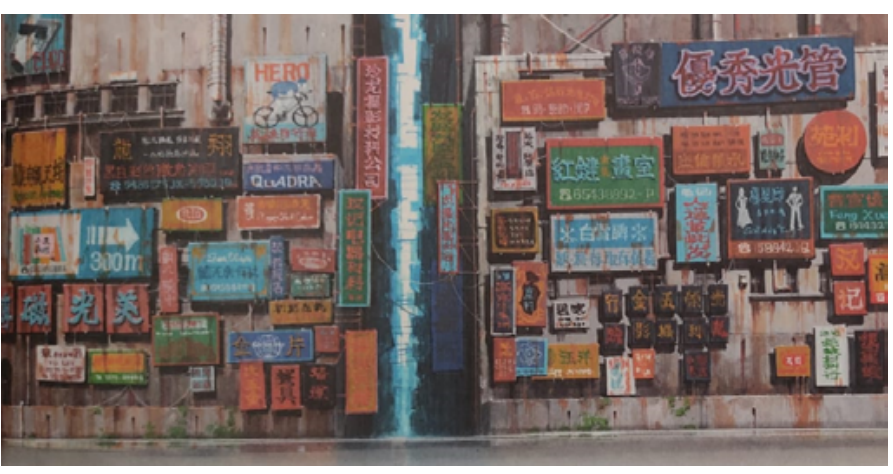

Figura 21. Kusamori, Shuichi. Ghost in the Shell. 1995

concordancia del carácter transmedia de la obra, la panorámica retrata la ciudad en muchos aspectos que se van desarrollando durante la cinta.

En esta primera instantánea se muestra una ciudad extensiva y de densidad variable, estando todos los rascacielos concentrados en una zona para que la urbe vaya diluyéndose de manera acelerada hasta unos límites urbanos que se pierden en el horizonte.

Cambiando a una escala de distrito, encontramos también en la cinta diferentes vistas generales de zonas concretas de la ciudad, en su mayoría realizadas a la altura de los ojos del protagonista, consiguiendo una inmersión plena del espectador en la escena. En ellas, las torres del distrito financiero están siempre presentes, un recordatorio constante de dónde reside el poder de la ciudad, ya sea mientras se pasea por los callejones y canales de los distritos periféricos, como durante las escenas de persecución y patrulla de la «Sección 9».

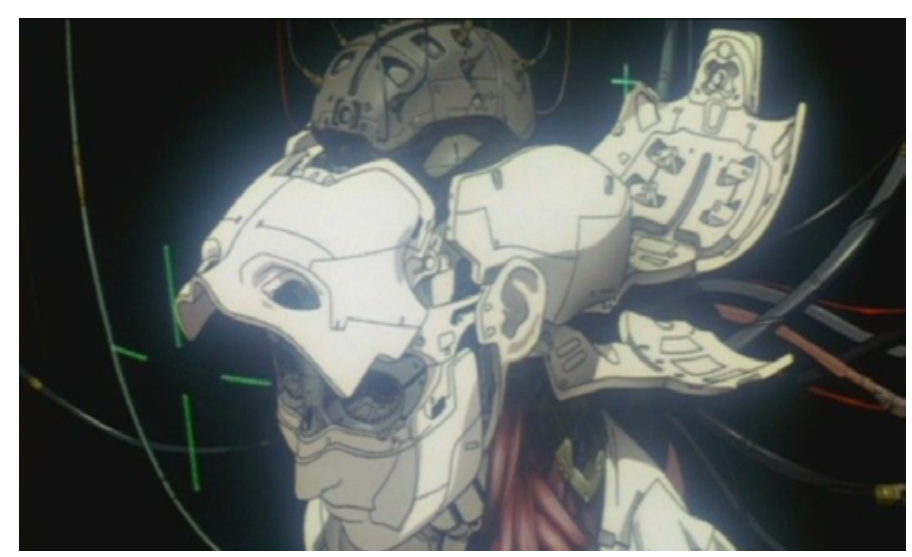

Figura 22. Oshii, Mamoru. Ghost in the Shell. 1995 
Cuando el film refleja los interiores de los edificios nos encontramos ante un planteamiento algo diferente. A diferencia de las imágenes de los exteriores, cargadas de emoción y mensaje, las imágenes del interior rara vez tienen un interés arquitectónico, salvo algunas excepciones.

Una de las escenas más impactantes del anime es la de sus créditos de inicio. En ella, se recrea el nacimiento artificial de la mayor Kusanagi, o al menos de su nuevo cuerpo cyberorgánico. Esta secuencia, de una belleza cinematográfica exquisita, muestra una arquitectura austera y en ocasiones ausente, teniendo únicamente detalles industriales y primando los elementos cilíndricos como sistemas de conducción de una factoría que lleva su producto hasta una suerte de fuente donde por fin el agua limpia y da vida a la nueva creación (Figura 21).

En cuanto a la vivienda, típicamente retratada en este tipo de obra, confirma una vez más la tendencia del género. Encontramos aquí dos ejemplos de vivienda dormitorio, en la cual apenas hay espacio para una cama, como lugar de refugio, pero muy lejos un ambiente que invite al esparcimiento doméstico. En ambos casos, tanto en la vivienda de la mayor (Figura 23) como en la del pobre diablo que ha sido víctima del «Marionetista», destaca el trato del hueco y la luz, sirviendo la ventana como marco de una ciudad lejana, esbelta y luminosa, que recuerda constantemente a sus moradores el lugar que les corresponde, completamente alejados de ella y entre las sombras.

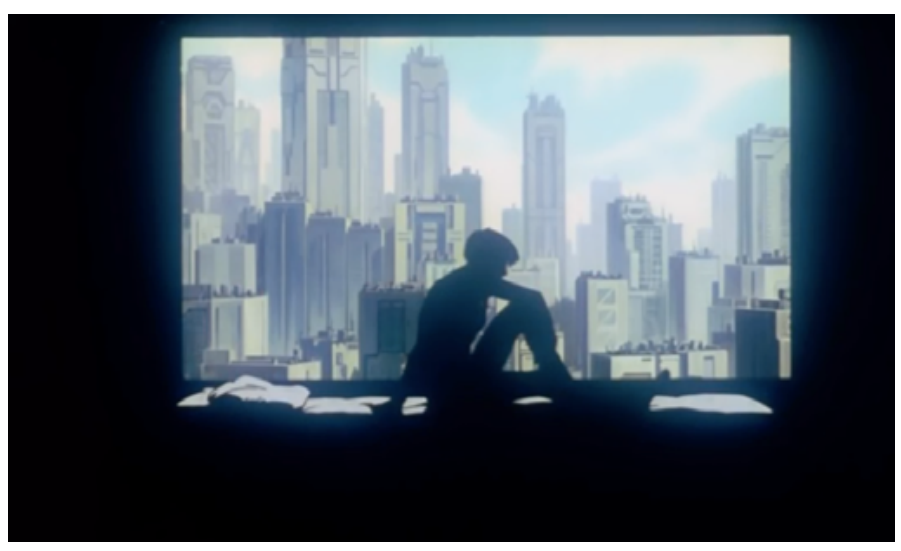

Figura 23. Oshii, Mamoru. Ghost in the Shell. 1995
El último gran hito arquitectónico remarcable de la película es la ubicación del clímax de la cinta en el Museo de Ciencias Naturales (Figura 24). Si tenemos en cuenta que la narración profundiza en cuál es la esencia del ser humano y qué es lo que nos separa de una inteligencia artificial si renunciamos a nuestro cuerpo orgánico, posiblemente no haya escenario mejor. El edificio, con una bóveda de cañón de vidrio, y una estética más cercana en ocasionas a la de un templo que a un espacio de exposiciones, está repleto de referencias a la creación y le evolución como son los fósiles diseminados por el lugar o el gran árbol de la vida de la cábala que preside el lugar, todo ello destruido en el momento de máxima tensión y dramatismo al final de la historia, cuando la mayor Kusanagi debe enfrentar por fin la verdad sobre su naturaleza dual.

\subsection{El mito de New Port City}

La ciudad en la que se desarrolla Ghost in the Shell ha pasado al imaginario colectivo por ser capaz de expresar visualmente los aspectos más importantes de la trama: la dualidad orgánico vs tecnológico, el distanciamiento extremo entre clases sociales y la implacable invasión tecnológica de cualquier aspecto de la vida.

Así pues, son señas de identidad que distinguen esta ciudad de otras del género su distrito periférico repleto de canales y espacios peatonales frente al distrito finan-

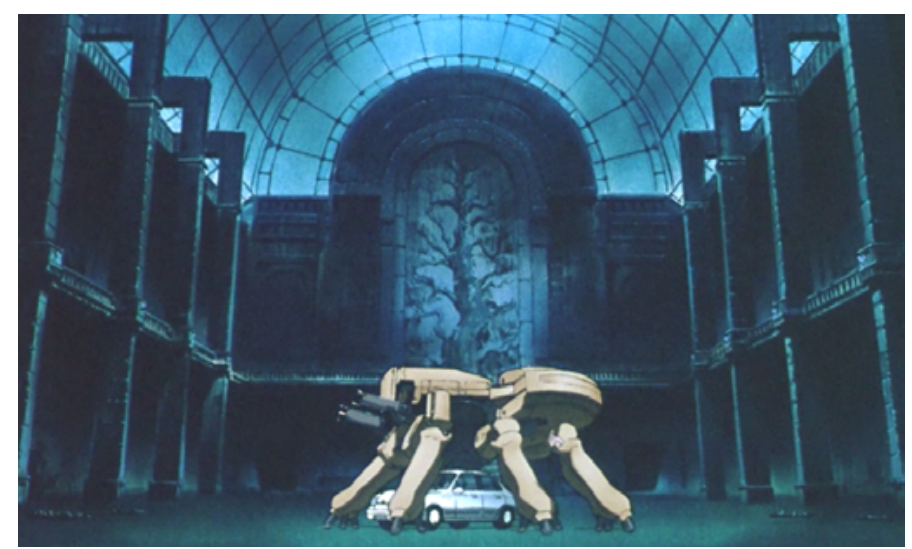

Figura 24. Oshii, Mamoru. Ghost in the Shell. 1995 
ciero, repleto de torres de vidrio y cuyas autovías multinivel han erradicado al peatón de la zona.

\section{Conclusiones}

Tras pasear por las calles de las diferentes versiones de Neotokio queda claro que existen puntos de unión entre los planteamientos de los autores, quienes aun perteneciendo a generaciones distintas vislumbran un futuro agónico para la capital del país del sol naciente.

Las versiones de la capital japonesa planteadas por Otomo, Anno y Shirow, aunque exageradas, tienen un punto de partida real y describen problemas de actualidad. La masificación, la minimización de la vivienda y la dependencia de la tecnología son temas tratados como mínimo de manera tangencial en estas obras, al igual que la paranoia social y la desconfianza de los sistemas de gobierno, trasladado a la ficción mediante el alzamiento de las megacorporaciones que desde la sombra controlan el poder como en el caso de NERV.

Otro de los aspectos destacables de los tres relatos expuestos anteriormente es la complejidad de su narración. Lejos de ser exclusivamente una sucesión de imágenes efectistas sobre un futuro más o menos plausible, los autores profundizan en cuestiones filosóficas abordadas desde diferentes puntos de vista: ¿Qué es lo que me hace humano? ¿Qué es lo que me define como individuo? ¿El desarrollo tecnológico nos hará libres o terminará por esclavizarnos?

Encontramos también paralelismos en lo que a planteamiento urbano se refiere. Desde una hipertecnificación en New Port City a una visión más relacionada con la decadencia en el Neotokio «otomoniano» pasando por la nada desdeñable ingeniería de Tokio-3, el desarrollo tecnológico se revela como indispensable en el crecimiento urbano, encontrando instalaciones imposibles en cada esquina. Sin duda el ejemplo paradigmático de este planteamiento será «La Ciudad» en la que se desarrolla Blame!, la obra magna de Tsutomu Nihei, en la cual una inteligencia artificial que ayudaba en la construcción

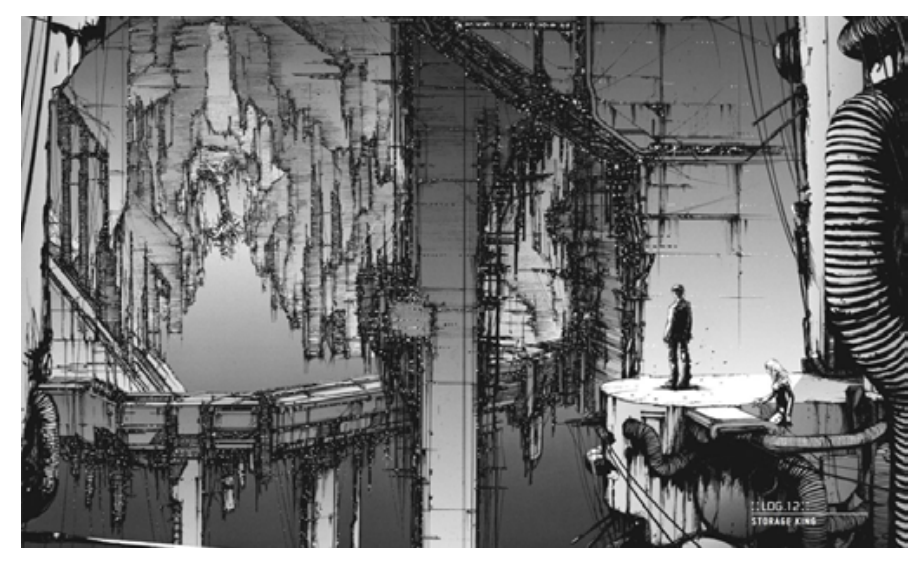

Figura 25. Nihei, Tsutomu. Blame! 1996

enloquece y acaba edificando el planeta completo creando una suerte de «Esfera de Dyson» (Figura 25).

En cuanto a la arquitectura propiamente, no es posible decir que exista un movimiento Cyberpunk sino que nos encontramos con un filtro social que, al aplicarse sobre una amalgama de estilos retro-futuristas, da como resultado una estética más o menos homogénea y reconocible que dota de identidad a las urbes de este género.

\section{Bibliografía}

3 Person View. Cyberpunk: Análisis de un género. 2018.

Barber, S. Ciudades proyectadas-Cine y espacio urbano. Gustavo Gili, 2006.

Bordes, Enrique. Cómic, arquitectura narrativa. Cátedra, 2017.

García Gómez, Francisco, y Gonzalo M. Pavés. Ciudades de Cine. Cátedra, 2014.

Gorostiza, Jorge. «Metrópolis» vs. «Ghost in the Shell»». Distopía y Cine - Futuro(s) Imperfecto(s), E.P.E. Donostia Kultura, 2017.

Heredia Pitarch, Daniel. Gainax y Hideaki Anno - La historia de los creadores de Evangelion. Diabolo Ediciones, 2019.

Hernández Pérez, Manuel. Manga, anime y videojuegos Narrativa cross-media japonesa. Prensas de la Universidad de Zaragoza, 2017.

Hideaki, Anno. Neon Genesis Evangelion. 1995. 
Katsushiro, Otomo. Akira. 2019. a ed., Norma Editorial, Napier, Susan J. «The Japanese Imagination of Disas1984.

Katsushiro, Otomo. Akira. Toho, 1988. ter from godzilla to Akira». Journal of Japanese Studies, 1993 , pp. 327-51.

Kishiro, Yukito. Gunnm - Battle Angel Alita. Belles Lettres, 2017.

Lammare, Thomas. «Born of Trauma: Akira and Capitalist Modes of Destruction». Positions: East Asia Cultures Critique, 2008.

Lus Arana, Luis Miguel. Futurópolis: el cómic y la construcción transmedia de la ciudad futura. Universidad de Navarra, 2013.

Masamune, Shirow. The Ghost in the Shell. 2017. a ed., Planeta Cómic, 1991.

Mur Vicente, Sergio. Anime y Cyberpunk: Visiones del Japón moderno en la serie Ghost in the Shell. Universidad de Zaragoza, 2019

Napier, Susan J. Anime from Akira to Howl's Moving Castle: Experiencing Contemporany Japanese Animation. Palgrave Macmilla, 2006.

Nihei, Tsutomu. Blame! Panini España, 2017.

Oshii, Mamoru. Ghost in the Shell. Manga Entertainment, 1995.

Palacios, Jesus. Conferencia Online «CIBERJAPON: futurismo, ciencia ficción y distopía en el anime». 2020.

Quetzal. Ánalisis de «Ghost in the Shell». 2017.

Riekeles, Stefan. Anime Architecture. Thames and Hudson Ltd, 2020.

Sadamoto, Yoshiyuki. Neon Genesis Evangelion. Norma Editorial, 2005.

Serrano García, Valentín. «Las ciudades imaginarias - Sueños entre las nubes y las cenizas». Ciudades de Cine, Cátedra, 2014.

VVAA. Neon Genesis Evangelion - Tv animation Production Art Collection. UDON Entertainment Inc., 2019. 